\title{
ARTICLES
}

\section{Narrowing Sex Differential in Life Expectancy in Canada and Austria: Comparative Analysis}

\author{
Frank Trovato*
}

\begin{abstract}
Throughout most of the $20^{\text {th }}$ century the sex gap in life expectancy in the industrialised countries widened in favour of women. By the early 1980s a reversal in the long-term pattern of this differential occurred in some countries, where it reached a maximum and thereafter has followed a declining trend. It is argued in this study that this development represents an emerging feature of the epidemiological profile of post-industrial societies. I look at Canada and Austria as two representative cases of this phenomenon over roughly three decades, between 1970 and 2001. Decomposition analysis shows that reduced sex differences in life expectancy in the 1980s and 1990s obtained mainly from the effects of reduced sex differences in mortality with respect to heart disease, and secondarily accidents and violence and lung cancer. Heart disease has played a larger role in Canada, whereas differential mortality from accidents and violence has been of greater importance in Austria. A further aspect of the investigation links sex differences in smoking prevalence to sex differences in life expectancy. A model is suggested that incorporates female labour force participation and a measure of gender role traditionalism in society as factors in female smoking prevalence. These variables are also postulated to correlate with change in the sex gap in life expectancy by a time lag of twenty years. It is found that sex differences in smoking prevalence in the past are related to sex difference in life expectancy in the present, and that female labour force participation and gender role traditionalism are also associated with the sex gap in expectation of life. The findings are interpreted in reference to epidemiological transition theory and the literature concerning change in the position of women and sex differences in mortality in high-income nations.
\end{abstract}

* Frank Trovato, Department of Sociology and Population Research Laboratory, University of Alberta, Edmonton, Canada, T6G 2H4. Email: Frank.Trovato@ualberta.ca 


\section{Introduction}

During the twentieth century mortality in the Western world and in Japan has declined to unprecedented levels (Coale 2003; Preston 1976; Tuljapurkar, Li and Boe 2000; White 2002; White and Preston 1996; Wilmoth 1998; Andreev 2000; Riley 2001). In this generalised context of improved survival, female life expectancy has surpassed that of males by an increasing margin (Madigan 1957; Stolnitz 1956; Enterline 1961; El-Badry 1969; Preston 1976; Retherford 1975; Waldron 1976, 1986, 1993; Lopez 1983; Vallin 1983, 1993; Nathanson 1984; Smith 1993; Rogers, Hummer and Nam 2000; Riley 2001; Salomon and Murray 2002; Luy 2003). ${ }^{1}$ At present, life expectancy at birth in the industrialised countries ranges in the upper seventies for men and above 80 years for women (Van Hoorn and Broekman 1999; Population Reference Bureau 2004). Figures 1 and 2 provide an illustration of the long-term trends in life expectancy at birth and the sex difference in this measure for Canada and Austria. ${ }^{2}$

Early in the $20^{\text {th }}$ century the differential in longevity in these two countries was between 3 and 4 years. ${ }^{3}$ By 1950 it had changed to about 4.5 years in Canada and to just over 5 years in Austria. ${ }^{4}$ By comparison, during this time in the United States the gap stood at almost six years (Smith 1993: 83; Peron and Strohmenger

1 The historical record can shed further light on the magnitude of the sex gap in survival in earlier times. During the latter part of the $18^{\text {th }}$ century, female life expectancy in European countries such as Sweden, France and England, exceeded male expectancy by a margin of about three years (Preston, Keyfitz and Schoen 1972; Stolnitz 1956). And during the mid to late $19^{\text {th }}$ century, life expectancy for men and women and corresponding female-male difference tended to range as follows: England and Wales (1841: male 40.19, female 42.18, difference $=$ 1.99); France (1817-31: male 38.33, female 40.83, difference $=2.50$; Sweden (1816-40: male 39.50 , female 43.56 , difference $=4.06)$; Germany $(1871-81$ : male 35.58 , female 38.45 , difference $=2.87$ ) (Acsadi and Nemeskeri 1970; Preston, Keyfitz, and Schoen 1972; UN Department of Economics and Social Affairs 1973: 116).

2 Canada and Austria share similarities in demographic and socioeconomic conditions. Ranking as two of the wealthiest nations in the world, they are demographically mature societies, with rates of natural increase of zero for Austria and 0.3 per cent for Canada in 2003 (Population Reference Bureau 2003). Following several decades of sustained sub-replacement fertility rates these populations have aged considerably, and their median ages are in the upper 30s.

3 In Figure 2, the sharp drop in the sex differential in 1921 in Canada seems unusual. It may reflect problems with the estimated historical life expectancy figures (i.e., not all provinces had yet been included in the national vital statistics system), or possibly the consequence of some event or condition in society that may have led to a temporary drop in the sex gap in life expectancy. In this connection, it is interesting to note that a similar situation has been documented for the United States, attributed to the greater female mortality during the influenza pandemic around this time in history (Smith 1993: 83; Noymer and Garenne 2000). Perhaps the Canadian case is reflective of this as well. The continuation of reduced differentials through the 1930s in Canada may signify differential mortality between men and women associated with the effects of the Great Depression.

4 For the latest period of observation in these two countries (Figure 2) the respective sex gaps are virtually identical to the values recorded in the mid 1950s (about 5.5 years). 
Figure 1:

Historical trend in male and female life expectancy at birth in Canada and Austria
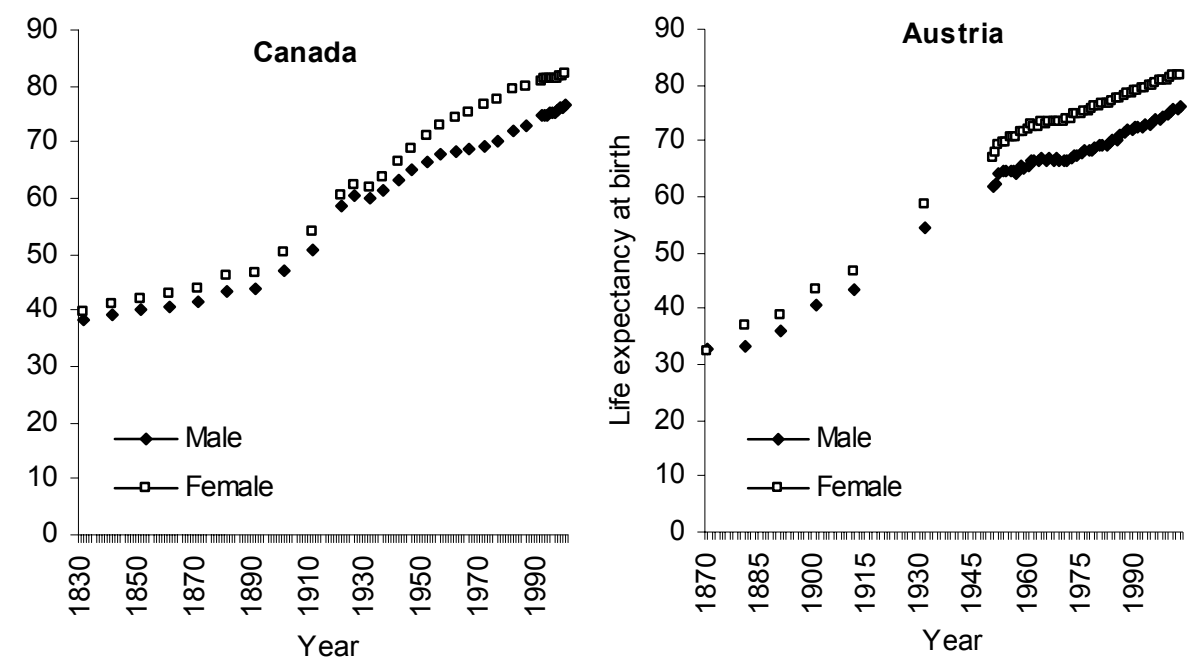

Sources: Peron and Strohmenger (1985: 115); Belanger (2003: 17); Nagnur (1986); Statistics Austria (2005: 79).

Figure 2:

Historical trend in the female-male difference in life expectancy at birth in Canada and Austria

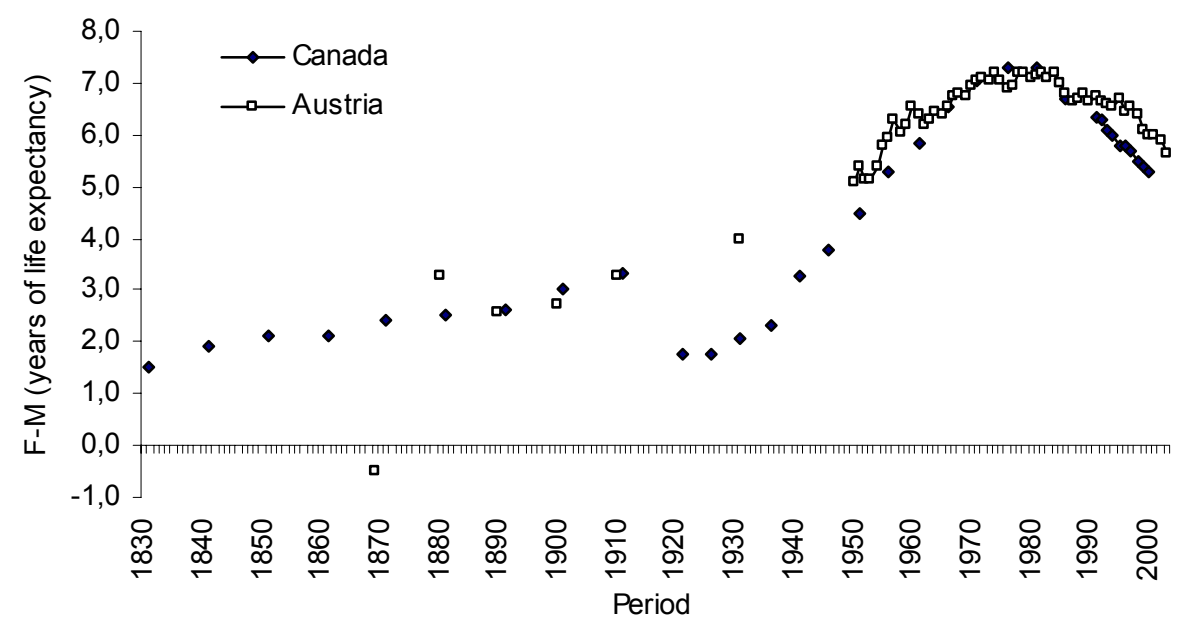


1985: 121), and it varied between 2 and 7 years across other industrialised countries (Lopez 1983). By 1970, the life expectancy differential had expanded to about 7 years in Canada and Austria; and in other cases (e.g., France and Finland) it had grown to 8 or 9 years (Lopez 1983: 86-87).

Table 1 looks at selected high-income countries for the period between the early 1970s and the late 1990s (in two cases 2000 and 2001). England and Wales led the way in the phenomenon under investigation. ${ }^{5}$ Between 1970 and 1980 their sex gap in life expectancy had reduced by 0.31 of a year. As shown in the table, this tendency would later spread to other countries. The exceptional case of Japan, where the sex gap has continued to expand in favour of women, is examined in a separate investigation.

\section{Study Objectives}

This investigation expands on recently published works in this area of mortality analysis (Trovato and Lalu 1996a, 1996b, 1998; Pampel 2002, 2003; Waldron 1993; Nathanson 1995). However, rather than examining an aggregate of countries, I look at the cases of Canada and Austria. The period of observation is roughly three decades, between 1970 and $2001 .{ }^{6}$ Observed sex differences in life expectancy in these two populations are decomposed into the relative contribution of ten major cause-of-death components. I situate the analysis in the context of epidemiological transition theory and explanations pertaining to gender role change and mortality in post-industrial societies. The question of how much of the observed narrowing in life expectancy in Canada and Austria can be attributed to sex differences in smoking-related mortality is also addressed. Lastly, I propose a conceptual model that relates factors associated with gender role change in society to female smoking prevalence, and the relevance of this variable to change in the sex differential in life expectancy.

$5 \quad$ Actually, Lopez (1983: 10) showed that beside England and Wales, a few other countries had experienced a small decline (by about 0.10 of a year) in their sex differentials in life expectation during the interval between 1970-74 and 1975-78.

6 These recently published works do not extend the period of observation beyond the early or mid-1990s. 
Table 1:

Sex differentials in life expectancy at birth in selected high-income countries; early 1970s - late 1990s/early 2000s

\begin{tabular}{|c|c|c|c|c|c|c|c|c|c|c|c|c|c|c|}
\hline \multirow[t]{2}{*}{ Country } & \multicolumn{2}{|c|}{ Early 1970 s } & \multicolumn{3}{|c|}{ Early 1980 s } & \multicolumn{3}{|c|}{ Early 1990s } & \multicolumn{3}{|c|}{$\begin{array}{c}\text { Late 1990s/early } \\
2000 \text { s }\end{array}$} & \multicolumn{3}{|c|}{$\begin{array}{c}\text { Change between } \\
\text { periods }\end{array}$} \\
\hline & Male Female & D1 & Male & Female & D2 & Male & Female & D3 & Male & Female & D4 & D2-D1 & D3-D2 & D4-D3 \\
\hline Canada & $\begin{array}{|ll|}69.48 & 76.65 \\
\end{array}$ & 7.17 & 71.92 & 79.24 & 7.33 & 74.44 & 81.00 & 6.56 & 76.87 & 82.22 & 5.35 & 0.16 & -0.77 & -1.21 \\
\hline Austria & $66.73 \quad 73.80$ & 7.07 & 69.23 & 76.46 & 7.23 & 72.75 & 79.36 & 6.60 & 76.06 & 81.88 & 5.82 & 0.11 & -1.12 & -0.24 \\
\hline USA & $\begin{array}{|ll|}67.23 & 74.73\end{array}$ & 7.50 & 70.30 & 78.00 & 7.70 & 71.91 & 78.97 & 7.07 & 74.08 & 79.47 & 5.39 & 0.20 & -0.64 & -1.68 \\
\hline England/Wales & 69.3075 .60 & 6.30 & 71.18 & 77.18 & 6.00 & 73.52 & 79.18 & 5.66 & 75.92 & 80.68 & 4.76 & -0.31 & -0.34 & -0.90 \\
\hline West Ger & $67.60 \quad 74.04$ & 6.45 & 70.28 & 77.03 & 6.75 & 73.02 & 79.50 & 6.48 & --- & --- & --- & 0.31 & -0.28 & --- \\
\hline Germany & --- & --- & --- & --- & --- & 72.06 & 78.60 & 6.55 & 74.89 & 81.01 & 6.11 & --- & --- & -0.43 \\
\hline taly & 68.8275 .05 & 6.22 & 71.58 & 78.24 & 6.66 & 73.73 & 80.47 & 6.74 & 76.27 & 82.58 & 6.31 & 0.44 & 0.08 & -0.43 \\
\hline France & 69.14 & 7.72 & 71.03 & 79.27 & 8.25 & 73.58 & 81.99 & 8.41 & 75.10 & 82.75 & 7.64 & 0.53 & 0.17 & -0.77 \\
\hline Sweden & $72.18 \quad 77.58$ & 5.40 & 73.16 & 79.33 & 6.16 & 75.14 & 80.82 & 5.68 & 77.08 & 82.01 & 4.92 & 0.76 & -0.48 & -0.76 \\
\hline Japan & $70.22 \quad 75.66$ & 5.45 & 74.08 & 79.64 & 5.56 & 76.28 & 82.71 & 6.43 & 77.20 & 84.08 & 6.88 & 0.11 & 0.87 & 0.46 \\
\hline
\end{tabular}

Note: D1, D2, D3, D4 represent period-specific differences in life expectancy at birth (female - male). The last three columns express the change (second order differences) of these differences across sequential periods. The actual time points for the countries are as follows: Canada (1971, 1981, 1991, 2000); Austria (1970, 1980, 1990, 2001); USA (1970, 1980, 1990, 1999); England and Wales (1971, 1980, 1991, 2000); West Germany (1970, 1980, 1991); Germany (1990, 1999); Italy (1970, 1980, 1990, 1999); France (1970, 1980, 1990, 1999); Japan (1970, 1981, 1990, 1999); Sweden (1970, 1980, 1990, 1999). East and West Germany were reunited in 1990; therefore after this date the World Health Organisation reports mortality data for Germany as a whole.

--- means data not available.

Source: Author's computations based on data from the World Health Organisation, www.who.org 


\section{Theoretical Framework}

\subsection{Sex Differences in Life Expectancy and Epidemiological Transition}

Notwithstanding the exceptional case of Japan, the tendency for a growing number of high-income nations to experience reduced sex differences in life expectancy over the past two decades can be viewed as a new feature of the epidemiological profile of post-industrial societies. The epidemiological transition theory explains the historical shift in mortality as countries experience modernisation, from a period in history when infectious and parasitic diseases dominate as the leading killers, to a stage where chronic and degenerative ailments become the predominant causes of death (Omran 1971). All societies in the Western world (including Japan) have passed through three stages, described by Omran (1971) as "the age of pestilence and famine," "the age of receding pandemics," and "the age of man-made and degenerative diseases." An important proposition in this theory states that with modernisation populations experience widening sex differences in mortality, resulting in faster life expectancy gains for females. The larger improvements in survivorship for females that occur with the recession of pandemics (stage II) are especially beneficial to infants and children of both sexes, and to females in the adolescent and reproductive age periods. And during the transition from infectious to degenerative disease predominance (stage III) "women switch from a level of mortality in the reproductive years higher than that of men to a level more advantageous, such that the female's higher relative risk of death disappears at about the level of 50 years life expectancy and becomes lower than that of males thereafter" (Omran 1971: 525). Omran's theory remains an important framework for the study of disease and mortality change. However, this formulation is silent with specific reference to the phenomenon of interest to this investigation. It does not anticipate that after a prolonged period of widening sex differences in life expectancy, nations would experience a pattern of reduced differences in this measure.

Extensions of Omran's theory (Olshansky and Ault 1986; Rogers and Hackenberg 1987; Caselli, Meslé and Vallin 2002; White 2002; Salomon and Murray, 2002) point to the continued predominance of chronic and degenerative diseases in the most advanced countries. A Fourth stage has been proposed, the "age of delayed degenerative diseases" (Olshansky and Ault 1986). In these populations a large proportion of deaths annually are caused by chronic and degenerative ailments, and consequently most deaths are concentrated in the older ages. The segment of the population which experiences the most pronounced improvements in survival probabilities are the elderly, as mortality in the younger ages and in infancy has reached historic low levels (Olshansky and Ault 1986). Taken together, these features of advanced societies imply that sex differences in life expectancy obtain principally from sex differences in mortality among older 
adults, and that chronic and degenerative diseases would account for most of the discrepancy in life expectancy between men and women.

Rogers and Hackenberg (1987) add that risky behaviours and lifestyle underlie a large proportion of deaths in contemporary high-income countries. For instance, in Canada, during 1995 about 15,000 people lost their lives to lung cancer, a disease connected to tobacco use. In the United States, the number of such cases exceeded 149,000; and in Austria, this cause accounted for over 3,000 deaths during the same year (World Health Organisation 1998). It is also true that a large number of accidental deaths are linked to alcohol and other substances, and that suicide and homicide continue to be significant causes of premature death among young and middle-aged adults (Stack 2000a, 2000b). These prevailing epidemiological trends in the advanced societies suggest the existence of a "hybristic" configuration of factors, whereby chronic diseases associated with aging and conditions related to poor life style and personal habits are mainly responsible for premature mortality (Rogers and Hackenberg 1987).

In tandem with these epidemiological features, advanced societies during the post-war years have also experienced major social demographic changes. The view has been expressed that such countries are actually in the midst of a "second demographic transition" (Van de Kaa 1987, 1999, 2004; Lesthaeghe and Surkyn 1988), characterised by a pluralisation of living arrangements among young adults and a pervasive tendency to postpone marriage, a large percentage of couples living in cohabiting unions, declining marriage rates, increased divorce probabilities, very high contraceptive prevalence levels, sub-replacement fertility rates, increased proportion of couples remaining childless, and an increasing tendency among couples for childbearing outside of traditional marriage. ${ }^{7}$ As part

It has also been suggested that these social demographic trends in postmodern society are supported by a cultural mindset among the young, characterised by a generalised mistrust toward established institutions and traditional sources of authority (Lesthaeghe and Surkyn 1988; Van de Kaa 1999, 2004). Although the second demographic transition perspective emphasises shifts in societal value systems that give rise to change in demographic behavior, most notably related to family formation and procreation, it does also consider-albeit to a lesser degree - issues pertaining to mortality and international migration. Van de Kaa (1999), the scholar most closely associated with the concept of "second demographic transition," has explicitly incorporated in his discussions elements of mortality and longevity expectations in the context of postmodern societies. For instance, he writes, “...[A] shift in value orientation provides a perfect explanation for the many demographic changes since $1965 \ldots$...I is consistent with an individualistic lifestyle in which people make their own choices about marriage or cohabitation, where they are free to have children in or outside marriage, to have them alone or with a partner, and where they can have them early or late in life. A lifestyle where it is understood that sex and marriage/union are no longer closely related, and that contraception is only interrupted to have a self-fulfilling conception. The value shift is also consistent with people adopting an optimal risk strategy to reduce the probability of premature illness and death. The idea of choosing a personal death in the case of terminal illness is also in line with this lifestyle. ..." (p. 31). Clearly, Van de Kaa's conceptualisation with respect to health and mortality in post-industrial contexts is not inconsistent with propositions expressed by epidemiological scholars (e.g., Rogers and Hackenberg 1987; Mokdad and colleagues 2004) on 
of this configuration of change, gender roles in these societies have become more egalitarian (Davis 1984; McDonald 2000). Could it be that part of the convergence in the sex differential in life expectancy noted recently in some countries is linked to changes associated with the status of women in these societies? In addressing this question, I restrict myself to a discussion of two strands of theorising, based largely on the recent works of Pampel $(2002,2003)$ and Nathanson (1995), though clearly the studies of others are also related (e.g., Waldron 1976, 1986, 1991a, 1991b, 1993; Veevers and Gee 1986; Verbrugge 1976). Pampel's research emphasises smoking diffusion as the mechanism underlying the recent reductions in death rates between men and women, whereas Nathanson's explanation includes additional factors, of which change in the position of women in society is of particular importance. ${ }^{8}$

\subsection{Change in the Position of Women, Smoking, and the Sex Differential in Life Expectancy}

In the context of widespread social change in the post-war years, women in the industrialised countries have moved away from unpaid work in the home and into the paid labour force. This has in general resulted in greater economic gain for women and their families (Repetti, Matthews, and Waldron 1989). However, as part of this transformation, women may also experience some less desirable consequences to their health. Aspects of their lifestyles may change; they may adopt some of the less positive features of the male gender role, and thereby acquire some of the mortality risks traditionally associated with men. To the extent that this is true, women would at some point begin to experience erosion in their advantage in longevity in relation to men (Nathanson 1995). One detrimental behaviour being increasingly adopted by women is cigarette smoking (Waldron 1991a, 1991b, 1995; Lopez, Caselli, and Valkonen 1995).

It has been postulated that the adoption of cigarettes by women may reflect in part a rejection of traditional norms for appropriate female behaviour (Waldron 1991b). In Nathanson's conceptual model, change in the position of women in society (in terms of division of labour, family status, political power) is viewed as a potential determinant of women's increased smoking prevalence, and this in turn is thought to translate into slower pace of life expectancy gains for women. Nathanson (1995) hypothesised that countries with relatively high levels of gender equality would have high levels of smoking prevalence among women,

the relevance of life style factors in determining health status in contemporary high-income countries.

8 Explanations for the sex differential in mortality emphasise a wide range of factors, from biological and genetic differences between the sexes to structural and sociological causes underlying differential behaviors of men and women. A review of this vast literature is avoided here due to space limitations (for more extensive reviews see Luy (2003); Waldron (1976, 1995, 2000); Perls and Fretts (1998); Owen (2002)). 
and that this in turn would result in slower gains in life expectancy at age 40 for women. Nathanson's cross-national analysis revealed that increased female labour force participation is inversely associated with change in female life expectancy at age 40; and in countries where female smoking prevalence in 1970 was relatively high, women's life expectancy gains between 1970 and 1988 were slower than in those countries characterised by low smoking prevalence. Thus, for example, Japan with very low female smoking rates showed the largest increases in female life expectancy between 1970 and 1988; and Denmark, with the highest smoking prevalence, had the slowest gain in female life expectancy during this period. However, according to Nathanson (1995), there results do not in themselves prove conclusively that greater levels of gender equity in society is associated with a slowdown in female life expectancy gains over time: "[N]either the data...presented nor the scenarios for the future...are consistent with the existence of a causal relationship between movement toward gender equality and women's mortality" (p. 154). A recent analysis of sex differences in accidental mortality across 18 high-income nations by Pampel (2001b) also failed to produce unequivocal support for the gender equity thesis.

In countries where the sex difference in life expectancy has narrowed, change in mortality from heart disease and lung cancer have contributed significantly to this (Trovato and Lalu 1996a, 1996b, 1998). These causes of death are known to be strongly associated with prolonged tobacco use (Doll and Peto 1981; McGinnis and Foege 1993; Mokdad et al. 2004; Peto et al. 1992, 2000; Ravenholt 1990; Bartecchi et al. 1994; Waldron 1976, 1986, 2000). It is estimated that smoking caused approximately 440,000 deaths in the United States during 2004 (Bombard et al. 2004). In the European Union, the number of male deaths from lung cancer in 2000 was close to 140,000 (Boyle et al. 2003).

The negative health effects of tobacco in a population are typically felt decades after the onset of widespread smoking (Hegmann et al. 1993; Lopez 1995; Nathanson 1995). In a study of 22 high-income countries between 1975 and 1995, Pampel (2002) tested this idea (i.e., smoking diffusion thesis) against the gender equity thesis as possible explanations for the convergence in sex difference in mortality rates. No support was found for the proposition that movement toward greater levels of gender equity is a factor in this trend. Support was found for the idea that rising levels of female smoking over the course of the latter part of the twentieth century, and the consequent lagged increases in female lung cancer and other smoking-related mortality in the 1970s and thereafter, fully accounts for the recently observed narrowing of the sex difference in mortality. Pampel (2002) concluded that all of the observed narrowing in the sex gap in mortality between 1975 and 1995 noted across industrialised countries has resulted from convergence in smoking prevalence between men and women: "The results...do not suggest that cigarette smoking fully accounts for the sex differential in mortality between males and females; rather, smoking fully explains the recent narrowing of the sex differential" (p. 96). Thus, according to 
Pampel (2002), the female relative advantage in life expectancy has fallen recently because of the adoption of smoking by an increasing proportion of women over past decades and the consequent lagged effects on their survival probabilities, plus reductions in smoking among men and consequent improvements in male mortality rates.

It should be noted however, that in addition to smoking-related diseases, in the industrialised countries accidents, violence, suicide, and cirrhosis of the liver also account for a large number of deaths annually (Peto et al. 1992; Mokdad et al. 2004; Pampel 2001b). These causes of premature mortality have little direct association with smoking, and tend to be heavily concentrated among young adults, with death rates being considerably greater in men (Owens 2002). ${ }^{9}$ For instance, death rates from accidents and adverse effects exceed female rates by a ratio of 3 to 1 or greater (Waldron 1976, 1993, 1983; Verbrugge 1976; Wingard 1984; Nathanson 1984; Perls and Frets 1998). ${ }^{10}$ Change in sex differences in mortality due to these causes may also account for narrowing sex differences in life expectancy.

\section{Hypotheses}

Of the six predictions listed below, the first two are associated with the points raised in connection with sex differences in life expectancy and epidemiological transition theory; the remaining four relate to the discussion surrounding the position of women in society, smoking, and sex differences in mortality.

1. Being in the most advanced stage of epidemiological transition, Canada and Austria would experience similar patterns of morbidity and mortality, whereby chronic/degenerative diseases are the dominant causes of death. Therefore, change in heart disease and cancer mortality should

9 This point is also acknowledged by Peto and associates (1992) in their extensive analysis of smoking-related mortality in the industrialised world (see also Waldron 1986).

10 For example, according to the World Health Organisation, in the United States during 1994, there were a total of 91,437 deaths linked to accidents and adverse effects. Of this total, over 60,000 deaths were males and almost 31,000 were females, accounting for a ratio of male to female deaths of about 2:1. In the same year, there were 31,142 suicides of which over 25,000 were males and close to 6,000 cases were females, for an approximate sex ratio of almost 6:1. The number of homicides was reported to have been 24,547 (19,342 males, and 5, 205 females, for a ratio of almost 4:1). Concerning the situation in Canada and Austria, in 1995 there were a total of 210,733 deaths in Canada, of which 8,820 occurred as a result of accidents and adverse effects, and the male to female ratio for this cause was almost 2:1. The corresponding ratios for suicide and homicide were about 4:1 and 2:1, respectively. In the same year, Austria recorded 81,171 deaths, and of this total almost 3,000 were due to accidents and adverse effects, and the sex ratio was approximately $2: 1$. Suicide accounted for 1,788 deaths, of which 1,333 were males and 455 were females, for a sex ratio of almost 3:1. An additional 84 deaths in Austria were homicides, of which 43 were male decedents (World Health Organisation 1988). 
account for a large part of narrowing sex differences in life expectancy in these nations.

2. In accordance with the notion that social pathologies also account for a significant number of deaths on annual basis in the industrialised countries (Rogers and Hackenberg 1987 McGinnis and Foege 1993; Mokdad et al. 2004), it is anticipated that change in external causes of death, namely suicide, accidents, violence, and cirrhosis of the liver, would also account for part of the decline in the sex gap in life expectancy in the two countries.

3. Although in the literature measures of change in the position of women in society have not been found to correlate significantly with female smoking (e.g., Nathanson 1995), I proceed to check whether this relationship exists in the specific contexts of Canada and Austria. It may be that the association varies from country to country and it may not always be detectable in the aggregate when a large number of populations are examined. It is proposed that an indicator of sex role traditionalism in society (explained below) will correlate strongly with female smoking prevalence in Canada and Austria: The more traditional the gender role context in society, the more socially restricted are women's lives, and consequently they would be less likely to smoke as compared to a modern context with relatively low levels of sex role traditionalism and fewer social constraints on women.

4. On the assumption that sex differences in smoking in the past underlie current sex differentials in mortality (Pampel 2002, 2003), I expect that change in smoking prevalence in the past in men and women will correlate with change in the sex difference in life expectancy. A rise in female smoking prevalence in relation to men would be expected to result in a narrowing of the sex gap in life expectancy eventually as a function of either increased mortality rates in women from smoking-related causes of death, or from a slowdown in their mortality improvements over time.

5. In some aggregate level analyses female labour force participation in high-income nations has been found to be positively associated with female longevity (Pampel and Zimmer 1989; Waldron 1991a). However, Nathanson (1995) found an inverse association between this measure and life expectancy gains for women at age 40 . Given these contradictory findings in the literature, a directional test of hypothesis is avoided here with respect to the possible association of this variable with change in the sex differential in life expectancy and also with regard to its relationships with female smoking prevalence.

6. Gender role traditionalism in society may be associated with the sex differential in life expectancy. In traditional contexts women's 
participation in the institutions of society outside of the family is limited as compared to men (Davis 1984; McDonald 2000), and this would protect women from some of the risks commonly faced by men (e.g., women would be less exposed to potential injuries and accidents on the road and at work and would commit suicide less frequently). ${ }^{11}$ It may be argued that with the erosion of the traditional "breadwinner system" (Davis 1984) the expansion of roles for women in society may result in some erosion of "protection" against certain types of risks, including those from accidents, homicide, and suicide (Durkheim 1887[1951]; Stack and Danigelis 1985). This suggests the hypothesis that the greater the level of gender role traditionalism in society, the wider the sex gap in longevity in favour of females.

Figure 3 synthesises the postulated relationships under hypotheses 3-6; it proposes that currently observed sex gaps in life expectancy (i.e., the female-male difference in life expectancy at birth at time $t$ ) are a function of sex differences in smoking, lagged twenty years (i.e., t-20) measured as the ratio of female to male smoking prevalence at $\mathrm{t}-20{ }^{12}$ Thus, for example, since the first observation for the sex difference in life expectancy in Austria is for 1970, the corresponding ratio of female to male smoking prevalence is for the year 1950; and if the current observation with respect to the sex gap in longevity pertains to 1980, then the corresponding lagged smoking prevalence ratio is for 1960, and so forth. This implies that the health eroding effects of smoking manifest themselves in the population by a time lag of about two decades (Canadian Cancer Society, 2005:6). ${ }^{13}$ Consistent with the third hypothesis, the proposed model specifies that

11 It may be interesting to consider certain aspects of Durkheimian theory on the differential social roles of women and men in society and the relevance of this on differential mortality risk. In Suicide, Durkheim (1887 [1951]) presents several arguments for the proposition that men and women are naturally different, and that this natural difference explains the differential roles of men and women in society. For example, Durkheim remarks that men "need restraint and [women] liberty" (p. 274) to imply that men have greater freedoms and degrees of involvement than do women in the everyday activities of society. This is why men commit suicide more frequently than women: "As she lives outside of community existence more than man, she is less penetrated by it; society is less necessary to her because she is less impregnated with sociability" (p. 215). Furthermore, Durkheim writes, "Being a more instinctive creature than man, woman has only to follow her instincts to find calmness and peace. She thus does not require so strict a social regulation as marriage..." (p. 272). It is instructive to note Durkheim's explanation for the greater tendency for men to commit suicide, homicide, and to also die more from accidents as compared to women: "[Woman] merely lacks as frequent opportunities, being less involved in the struggles of life. The causes impelling to sanguinary crimes affect her less than man because she is less within their sphere of influence. For the same reason she is less exposed to accidental forms of death..." (p. 342).

12 Although this model does not explicitly include societal factors, it is recognised that measures of a country's economic standing and other societal indicators would bear exogenous effects on the postulated relationships (Nathanson 1995).

13 Smoking-related mortality is rare before the age of 35 (Peto et al. 1992). 
Figure 3:

Proposed conceptual model of the macro level relationships of gender role traditionalism in society, smoking prevalence, and the sex differential in life expectancy

$(+)$

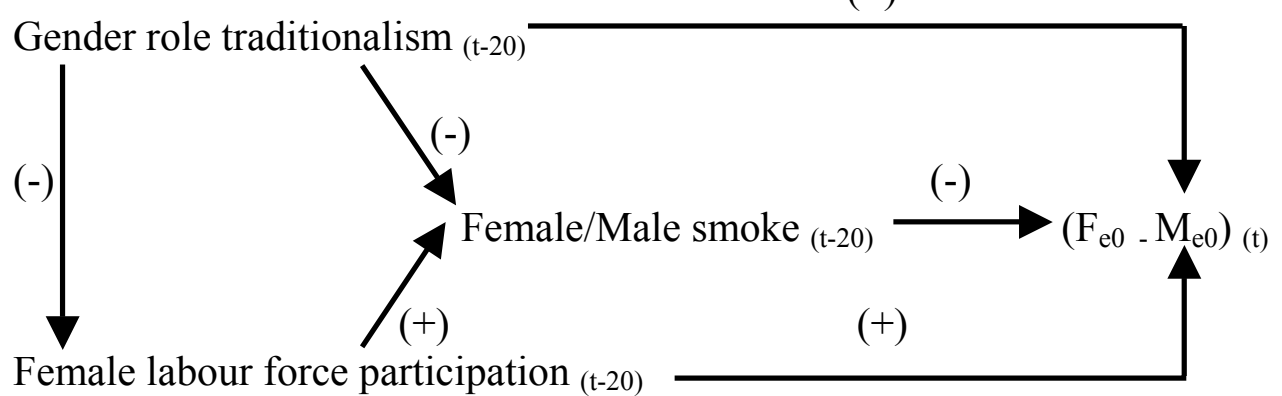

the ratio of female to male smokers at t-20 is inversely related to gender role traditionalism in society at $\mathrm{t}-20$ years ago. This assumes that in more traditional historical contexts smoking is generally discouraged for women, and relatively few women would partake in this type of behaviour as compared to less traditional contexts. The female labour force participation rate at $\mathrm{t}-20$ is included as a possible predictor of female smoking at t-20, though as stated earlier, it is uncertain whether this variable would actually shown an association with smoking. The model also specifies that the participation of women in the paid economy is inversely related to the level of gender role traditionalism in society.

\section{Decomposition of Sex Differences in Life Expectancy}

Hypotheses 1 and 2 are evaluated through a decomposition methodology, which takes the observed difference in the female-male life expectancy at birth and breaks it down into the contribution of sex differences in mortality with respect to ten cause-of-death components (described below). A cause component can have a positive or negative contribution. The sum of cause contributions adds up to the observed sex difference in life expectancy. ${ }^{14}$ Mortality and population data for

14 To elaborate further, consider the hypothetical case where only two causes of death wholly determine life expectancy in the population, and thus the expectation of life at birth is a function of two cause-specific vector factors for ages 0 through to the last age in the life table. The expectations of life at birth for males and females can be expressed as, $\mathrm{e} 0$ males $=\mathbf{F}(\mathbf{A}, \mathbf{B})$, and $\mathrm{e}_{\text {females }}=\mathbf{F}(\mathbf{a}, \mathbf{b})$, were, $\mathbf{A}$ is the vector of age-specific probabilities of death from cause 1 for males, $\mathbf{B}$ is the vector of age-specific probabilities of death from cause 2 for males, a is the vector of age-specific probabilities of death from cause 1 for females, and $\mathbf{b}$ is the vector of age-specific probabilities of death from cause 2 for females. These vectors can be rearranged 
this part of the analysis were taken from the World Health Organisation's electronic database (www.who.org). This source provides detailed mortality information for a large number of countries by cause of death, age, and sex and corresponding populations for the computation of death rates. Deaths were classified into ten cause components: (1) Heart Disease, (2) Other Diseases of the Circulatory System, (3) Lung Cancer, (4) Breast Cancer, (5) Prostate Cancer, (6) All Other Cancers, (7) Cirrhosis of the Liver, (8) Accidents and Violence excluding Suicide, (9) Suicide, (10) all other causes of death (see Appendix A). ${ }^{15}$ Four discrete time points are examined (1970, 1980, 1990 and 2001 for Austria; $1971,1981,1991$ and 2000 for Canada). ${ }^{16}$

Tables 2 and 3 display the decompositions for Canada and Austria, respectively. Included are sex-specific life expectancies at birth across four discrete periods, the corresponding female-male differences, the change in the sex gaps across sequential periods, and the cause of death contributions to these associated changes. These results are shown in terms of actual years of life expectancy and also in terms of their percentage distributions. The use of percentages is to help in the interpretation of relative importance of given causes of death, recognising that reliance on percentages in this case can be problematic because theoretically it is possible for one cause of death to contribute more than the actual difference being decomposed when the other causes contribute negatively. The first four columns in the tables list the contribution of given cause components to observed sex gaps in life expectancy within periods, whereas

algebraically in the context of cause-eliminated life tables to decompose the difference in expectation of life into the contribution of the two cause-of-death components (Das Gupta 1993),

$$
\begin{aligned}
{\left[\mathrm{e}^{0} \text { females }_{-\mathrm{e} 0} \text { males }_{\text {f }}\right] } & =\mathbf{F}(\mathbf{a}, \mathbf{b})-\mathbf{F}(\mathbf{A}, \mathbf{B}) \\
& =[\mathbf{F}(\mathbf{a}, \mathbf{b})-\mathbf{F}(\mathbf{A}, \mathbf{b})+\mathbf{F}(\mathbf{a}, \mathbf{B})-\mathbf{F}(\mathbf{A}, \mathbf{B})] / 2 \\
& +[\mathbf{F}(\mathbf{a}, \mathbf{b})-\mathbf{F}(\mathbf{a}, \mathbf{B})+\mathbf{F}(\mathbf{A}, \mathbf{b})-\mathbf{F}(\mathbf{A}, \mathbf{B})] / 2
\end{aligned}
$$

15 As with any study based on official death records, one must be fully aware of the possibility that the accuracy of diagnosis, reporting and coding causes of death can vary significantly across countries. As well, periodic revisions to the International Classification of Disease (ICD) system could artificially influence the time trend of rates for some causes of death. A detailed analysis of comparability of cause of death between the ICD-9 and ICD-10 based on United States death records by Anderson and associates (2001) shows that the discontinuity in causeof-death trend from implementing the ICD-10 revision are substantial for some causes of death (e.g., Septicemia, Influenza/pneumonia, Alzheimer's disease, Nephritis, nephrotic syndrome and nephrosis). For the causes of death in the present investigation, the comparability ratios computed by Anderson and colleagues (2001) were all very close to 1.0 (i.e., no or relatively little discontinuity).

16 From age-sex-cause specific death rates abridged multiple decrement life tables were computed, and these served as the basis for the decomposition analysis by cause of death. (Johnson and Eland-Johnson 1980; Namboodiri and Suchindran 1987; Keyfitz 1968; Preston, Keyfitz and Schoen 1972; Pollard 1988; Yanagishita and Guralnik 1988). 
columns 5, 6 and 7 reflect change in cause contribution between sequential periods, to either widen or narrow the sex differential.

Table 2:

Decomposition of the female-male differential in life expectancy at birth (e0) by period and its change due to ten cause of death components; Canada, 1971 to 2000

\begin{tabular}{|c|c|c|c|c|c|c|c|}
\hline & \multicolumn{4}{|c|}{ Period } & \multicolumn{3}{|c|}{$\begin{array}{c}\text { Change across } \\
\text { sequential periods }\end{array}$} \\
\hline & $(1)$ & (2) & (3) & (4) & $(5)$ & $(6)$ & $(7)$ \\
\hline & 1971 & 1981 & 1991 & 2000 & $\begin{array}{c}1971- \\
1981\end{array}$ & $\begin{array}{c}1981- \\
1991\end{array}$ & $\begin{array}{c}1991- \\
2000\end{array}$ \\
\hline Female e 0 & 76.649 & 79.244 & 80.999 & 82.216 & 2.595 & 1.755 & 1.217 \\
\hline Male e0 & 69.479 & 71.915 & 74.438 & 76.869 & 2.436 & 2.523 & 2.431 \\
\hline Female e 0 - Male e 0 & 7.170 & 7.329 & 6.561 & 5.347 & 0.159 & -0.768 & -1.214 \\
\hline \multicolumn{8}{|c|}{ Decomposition (years of life expectancy) } \\
\hline Heart disease & 2.956 & 2.800 & 2.067 & 1.468 & -0.156 & -0.733 & -0.599 \\
\hline Other circulatory & .394 & .403 & .352 & 0.302 & 0.009 & -0.051 & -0.050 \\
\hline Lung cancer & .681 & .885 & .838 & 0.527 & 0.204 & -0.047 & -0.311 \\
\hline Breast cancer & -.493 & -.535 & -.596 & -0.511 & -0.042 & -0.061 & 0.085 \\
\hline Prostate cancer & .228 & .286 & .394 & 0.364 & 0.058 & 0.108 & -0.030 \\
\hline Other cancers & .344 & .591 & .742 & 0.838 & 0.247 & 0.151 & 0.096 \\
\hline Cirrhosis of the liver & .145 & .188 & .140 & 0.120 & 0.043 & -0.048 & -0.020 \\
\hline Accidents/violence (-suicide) & 1.415 & 1.131 & .770 & 0.615 & -0.284 & -0.361 & -0.155 \\
\hline Suicide & .272 & .394 & .432 & 0.364 & 0.122 & 0.038 & -0.068 \\
\hline Other causes of death & 1.228 & 1.186 & 1.422 & 1.260 & -0.042 & 0.236 & -0.162 \\
\hline Total & 7.170 & 7.329 & 6.561 & 5.347 & 0.159 & -0.768 & -1.214 \\
\hline \multicolumn{8}{|c|}{ Decomposition (in percentage terms) } \\
\hline Heart disease & 41.23 & 38.21 & 31.50 & 27.45 & -3.02 & -6.71 & -4.05 \\
\hline Other circulatory & 5.50 & 5.50 & 5.37 & 5.65 & 0.00 & -0.13 & 0.28 \\
\hline Lung cancer & 9.50 & 12.08 & 12.77 & 9.86 & 2.58 & 0.69 & -2.92 \\
\hline Breast cancer & -6.88 & -7.30 & -9.09 & -9.56 & -0.42 & -1.79 & -0.47 \\
\hline Prostate cancer & 3.18 & 3.90 & 6.00 & 6.81 & 0.72 & 2.10 & 0.80 \\
\hline Other cancers & 4.80 & 8.07 & 11.31 & 15.67 & 3.27 & 3.24 & 4.36 \\
\hline Cirrhosis of the liver & 2.02 & 2.56 & 2.13 & 2.24 & 0.54 & -0.43 & 0.11 \\
\hline Accidents/violence (-suicide) & 19.73 & 15.43 & 11.73 & 11.50 & -4.30 & -3.70 & -0.23 \\
\hline Suicide & 3.80 & 5.38 & 6.59 & 6.81 & 1.58 & 1.21 & 0.22 \\
\hline Other causes of death & 17.12 & 16.17 & 21.69 & 23.56 & -0.95 & 5.52 & 1.89 \\
\hline Total & 100.00 & 100.00 & 100.00 & 100.00 & 0 & 0 & 0 \\
\hline
\end{tabular}

Source: Author's computations based on data from the World Health Organisation, www.who.org . 


\section{Decomposition by Cause of Death}

As noted in these tables, Canada and Austria have seen their respective sex gaps reduce from just over seven years in the early 1970s, to 5.35 years in Canada in 2000, and to 5.82 years in Austria in 2001. Between the early 1980s and the early $1990 \mathrm{~s}$, the difference narrowed by 0.77 of a year in Canada and by 0.58 of a year in Austria. Further constrictions of the difference were recorded in the final decade of the $20^{\text {th }}$ century, by 1.21 of a year in Canada and by 0.78 of a year in Austria.

Within each of the four periods examined, sex differences in heart disease mortality (i.e., higher male than female death rates) account for a large portion of the differentials in life expectancy. ${ }^{17}$ Given the dominance of this cause of death in the industrialised countries, this is not unexpected. ${ }^{18}$ Across periods, this cause component explains roughly 27 to 41 per cent of the observed sex gaps in Canada, and between 24 and 31 per cent in Austria. In actual years of life expectancy, these translate into contributions ranging between 2.96 years (in 1971 Canada) to 1.70 years (in 1970 Austria). By the early stages of the new century, the contribution of this cause component had dropped to about 1.50 and 1.70 years in Canada and Austria, respectively. Thus, the impact of heart disease as a factor in the sex difference in life expectation has declined with time, most notably since the early 1980s. In substantive terms, this indicates the occurrence of substantial reductions in the sex differential in mortality from this disease during this time interval, and therefore constitutes an important reason underlying the occurrence of reduced sex gaps in the average length of life.

Sex differences in mortality from accidents and violence (excluding suicide) also explain a substantial portion of the sex differences in life expectancy. In Canada, this cause of death contributed between roughly 11 and 20 per cent across periods (or approximately between 1.42 years of life expectancy in 1970, and 0.62 of a year in 2000). The influence of this component in Austria ranged between 12 and 24 per cent (in 2001 and 1970, respectively). In actual years,

Male death rates are generally higher than female death rates from major causes of death such as heart disease, lung cancer, most other cancers, accidents and violence, and suicide. Therefore, reduced contributions of a given cause component to the sex gap in life expectancy over time in the decomposition analysis would reflect varying degrees of convergence in male and female death rates from a given cause. In the contexts of Canada and Austria, for the periods examined this obtains from greater male gains in survival relative to women under the condition where both sexes improve their survival probabilities over time. Breast and prostate cancers are unique in that they are sex-specific (breast cancer afflicts predominantly women; prostate cancer is strictly a male disease). Improvement in survival probabilities from breast cancer would, all other things being equal, serve to widen the sex gap in life expectancy in favour of women, whereas reductions in prostate cancer mortality, all other things being equal, would help narrow the female-male differential in life expectancy.

18 As an illustration, in 1995, deaths due to acute myocardial infarction and other ischemic heart disease accounted for about 21 per cent of all deaths in Canada and Austria, respectively (World Health Organisation 1998). 
Table 3:

Decomposition of the female-male differential in life expectancy at birth (e0) by period and its change due to ten cause of death components; Austria, 1970 to 2001

\begin{tabular}{|c|c|c|c|c|c|c|c|}
\hline & \multicolumn{4}{|c|}{ Period } & \multicolumn{3}{|c|}{$\begin{array}{c}\text { Change across } \\
\text { sequential periods }\end{array}$} \\
\hline & (1) & (2) & (3) & (4) & $(5)$ & (6) & $(7)$ \\
\hline & 1970 & 1980 & 1990 & 2001 & $\begin{array}{c}1970- \\
1980\end{array}$ & $\begin{array}{c}1980- \\
1990\end{array}$ & $\begin{array}{l}1990- \\
2001\end{array}$ \\
\hline Female e 0 & 73.803 & 76.458 & 79.355 & 81.880 & 2.655 & 2.897 & 2.525 \\
\hline Male e0 & 66.732 & 69.277 & 72.754 & 76.058 & 2.495 & 3.477 & 3.304 \\
\hline Female e 0 - Male e0 & 7.071 & 7.181 & 6.601 & 5.822 & 0.110 & -0.580 & -0.779 \\
\hline \multicolumn{8}{|c|}{ Decomposition (years of life expectancy) } \\
\hline Heart disease & 1.698 & 2.128 & 1.994 & 1.785 & 0.430 & -0.134 & -0.209 \\
\hline Other circulatory & 0.504 & 0.518 & 0.426 & 0.336 & 0.014 & -0.092 & -0.090 \\
\hline Lung cancer & 0.664 & 0.706 & 0.739 & 0.636 & 0.042 & 0.033 & -0.103 \\
\hline Breast cancer & -0.311 & -0.386 & -0.485 & -0.302 & -0.075 & -0.099 & 0.035 \\
\hline Prostate cancer & 0.153 & 0.211 & 0.302 & 0.322 & 0.058 & 0.091 & 0.020 \\
\hline Other cancers & 0.316 & 0.550 & 0.762 & 0.815 & 0.234 & 0.212 & 0.053 \\
\hline Cirrhosis of the liver & 0.443 & 0.493 & 0.496 & 0.352 & 0.050 & 0.003 & -0.144 \\
\hline Accidents/violence (-suicide) & 1.682 & 1.287 & 0.916 & 0.700 & -0.395 & -0.371 & -0.216 \\
\hline Suicide & 0.426 & 0.574 & 0.500 & 0.437 & 0.148 & -0.074 & -0.063 \\
\hline Other causes of death & 1.496 & 1.101 & 0.951 & 0.890 & -0.395 & -0.150 & -0.061 \\
\hline Total & 7.071 & 7.181 & 6.601 & 5.822 & 0.110 & -0.580 & -0.779 \\
\hline \multicolumn{8}{|c|}{ Decomposition (in percentage terms) } \\
\hline Heart disease & 24.01 & 29.63 & 30.21 & 30.66 & 5.62 & 0.57 & 0.45 \\
\hline Other circulatory & 7.13 & 7.21 & 6.45 & 5.92 & 0.08 & -0.76 & -0.68 \\
\hline Lung cancer & 9.39 & 9.83 & 11.20 & 10.92 & 0.44 & 1.36 & -0.27 \\
\hline Breast cancer & -4.40 & -5.38 & -7.35 & -7.73 & -0.98 & -1.97 & -0.38 \\
\hline Prostate cancer & 2.16 & 2.94 & 4.58 & 5.52 & 0.78 & 1.64 & 0.96 \\
\hline Other cancers & 4.47 & 7.66 & 11.54 & 13.99 & 3.19 & 3.88 & 2.45 \\
\hline Cirrhosis of the liver & 6.27 & 6.87 & 7.51 & 6.05 & 0.60 & 0.65 & -1.47 \\
\hline Accidents/violence (-suicide) & 23.79 & 17.92 & 13.88 & 12.03 & -5.87 & -4.05 & -1.85 \\
\hline Suicide & 6.02 & 7.99 & 7.57 & 7.51 & 1.97 & -0.42 & -0.07 \\
\hline Other causes of death & 21.16 & 15.33 & 14.41 & 15.28 & -5.83 & -0.93 & 0.88 \\
\hline Total & 100.00 & 100.00 & 100.00 & 100.00 & 0 & 0 & $\overline{0}$ \\
\hline
\end{tabular}

Source: Author's computations based on data from the World Health Organisation, www.who.org .

these reflect contributions of between 0.70 of a year in 2001, and 1.68 years in 1970. As is the case with heart disease, these trends for differential mortality due to accidents and violence (excluding suicide) indicate that Canadian and Austrian 
men in recent years have managed to close some of their risk disadvantage in relation to women with respect to this cause of premature death.

With reference to lung cancer, its pattern of change in contribution across time periods also underlies the occurrence of reduced sex gaps in mortality. This is especially evident since the early 1990s in Austria, and since the early 1980s in Canada (see columns 6 and 7 of Tables 2 and 3). The contribution of declining sex differences in lung cancer mortality to the narrowing of the sex gap in longevity is notably stronger in Canada, however. A large part of this relates to the stage of the lung cancer epidemic for men and women in these countries. In Canada, the trend toward convergence in mortality risk from lung cancer between men and women began earlier. By the early 1980s, the pace of change in lung cancer mortality rates in Canadian men had slowed while that of women had gained momentum. In Austria, this development seems to have started about a decade later, around the early part of the 1990s.

As would be expected, given their sex specificity, the contribution of breast cancer mortality to the life expectancy differential is consistently negative within periods, whereas that of prostate cancer is consistently positive. However, the change in the contribution of these two components across time periods can be either positive or negative in terms of their effects on the sex gap in life expectancy. As indicated in Tables 2 and 3 (columns 5, 6 and 7), in both Canada and Austria, breast cancer contributed to a narrowing of the difference in longevity between 1970/71 and 1990/91, but widened this difference between 1990/91 and 2000/2001. This indicates that during this most recent period, there have been some declines in breast cancer mortality among women. In the case of prostate cancer, its change over time has been to widen the sex differential in life expectancy in favour of women (though during the most recent interval in Canada, there is evidence of a negative contribution). It should be mentioned that notwithstanding these effects, the contributions of these two cause components are generally small. As far as "other" cancers are concerned, sex differences in death rates from this cause category have been diverging, to expand the female advantage in life expectancy in relation to men, though at a diminishing degree of change across time. In other words, men continue to experience higher mortality rates from "other" cancers than do women, but over time the male excess mortality in relation to women has been getting smaller, though not sufficiently so to produce a negative contribution to the sex difference in overall life expectancy.

The effect of sex differences in mortality from cirrhosis of the liver in the 1990s has been to diminish the gap in expectation of life in both Canada and Austria. Concerning suicide, its contribution in Austria has ranged between roughly 0.43 (in 1970 and 2001) and 0.57 of a year (in 1980) of the sex differential in life expectation, while in Canada this has been smaller, between 0.27 and 0.36 of a year (in 1971 and 2000, respectively). As reflected in these figures, some convergence in suicide risk has occurred over time between men and women in these two populations, translating into small contributions toward 
closing some of the discrepancy in life expectancy between men and women. This effect is noted for Canada between 1991 and 2000, and in Austria between 1980 and 2001. Finally, with reference to "other" causes of death (residual), the effect has been to narrow the sex gap in Austria between periods, while in Canada its contribution has been irregular. What is similar across the two populations is that in the latest interval of observation the influence of this component has been to narrow the sex difference in life expectancy, by 0.16 of a year in Canada, and by 0.06 of a year in Austria. ${ }^{19}$

Table 4 looks at the contributions of cause components to the change in the longevity gap between 1980/81 and 2000/2001 in Canada and Austria, respectively. This interval covers the change in the differential from the approximate point at which it had reached a maximum to the most recent period of observation for which data are available for the two countries. ${ }^{20}$ During this time span the sex gap narrowed by almost two years (1.98) in Canada and by 1.35 years in Austria.

As far as Canada is concerned, most of this reduction in the female-male difference in longevity is attributable to declines in sex differences in heart disease mortality (i.e., by 1.33 years of life expectancy-a $67 \%$ contribution), and to a lesser degree to reduced sex differences in mortality from accidents and violence ( 26 per cent contribution), lung cancer (18 per cent contribution), "other" circulatory conditions ( 5 per cent contribution), cirrhosis of the liver ( 3 per cent contribution), suicide ( 1.5 per cent contribution), and "other" causes (3.7 per cent contribution). The three remaining cause components show positive contributions to widen the gap in favour of females. For the most part, however, these effects tend to be relatively minor (with the exception of "other" cancers, whose impact is about 12 per cent).

Unlike the situation in Canada, in Austria the most significant factor in accounting for the observed narrowing of the sex difference in life expectancy between 1980 and 2001 was not heart disease, but accidents and violence (excluding suicide). Change in this component alone helped close the sex gap in longevity by 0.59 of a year ( 43 per cent contribution), whereas change in heart disease mortality accounted for 0.34 of a year ( 25 per cent contribution). Another important contributing effect is associated with "other" circulatory diseases (13 per cent contribution). Nonetheless, if one were to combine the contributions of heart disease and "other" circulatory components, their impact on the sex differential would still be lower than that of accidents and violence. Lung cancer as a component accounted for only about 5 per cent of the observed reduction in

9 Ideally, this broad category of mortality would be disaggregated into its component parts for a more complete analysis.

20 One should distinguish between the "historical" maximum point of the differential, and the "maximum point" of the data analysed. The two many not be identical. However, as can be seen in Figure 2, these two time points in our case are quite close, as in both cases the historical peak point of the differential took place between 1976 and 1981. 
the sex gap. Suicide and cirrhosis of the liver show fairly important contributions, each accounting for approximately a 10 per cent reduction in the sex differential in longevity. Two cause components show positive contributions; these are prostate cancer ( 8 per cent) and "other" cancers, the latter being substantial (20 per cent).

Table 4:

Change in the contribution of ten cause-of-death components to the change in female-male difference in life expectancy at birth between the peak period of the differential and the latest time point of observation; Canada and Austria

\begin{tabular}{lcr}
\hline Canada & \multicolumn{2}{c}{$\begin{array}{c}\text { Contribution to the change in F-M } \\
\text { gap in life expectancy between 1981 }\end{array}$} \\
Cause component & and 2000 (years of life expectancy) & \multicolumn{1}{c}{$\%$} \\
\hline Heart disease & -1.332 & -67.2 \\
Other circulatory & -0.101 & -5.1 \\
Lung cancer & -0.358 & -18.1 \\
Breast cancer & 0.024 & 1.2 \\
Prostate cancer & 0.078 & 3.9 \\
Other cancers & 0.247 & 12.5 \\
Cirrhosis of the liver & -0.066 & -3.4 \\
Accidents/violence (-suicide) & -0.516 & -26.0 \\
Suicide & -0.030 & -1.5 \\
Other causes of death & -0.074 & -3.7 \\
\hline Total change & $-\mathbf{1 . 9 8 2}$ & 100.0 \\
\hline & Contribution to the change in F-M \\
Austria & gap in life expectancy between 1980 & \\
Cause component & and 2001 (years of life expectancy) & $\%$ \\
\hline Heart disease & -0.343 & -25.2 \\
Other circulatory & -0.182 & -13.4 \\
Lung cancer & -0.070 & -5.2 \\
Breast cancer & -0.064 & -4.7 \\
Prostate cancer & 0.111 & 8.1 \\
Other cancers & 0.265 & 19.5 \\
Cirrhosis of the liver & -0.141 & -10.4 \\
Accidents/violence (-suicide) & -0.587 & -43.2 \\
Suicide & -0.137 & -10.1 \\
Other causes of death & -0.211 & -15.5 \\
\hline Total change & $-\mathbf{1 . 3 5 9}$ & 100.0 \\
\hline & & \\
Not A n & & \\
\hline
\end{tabular}

Note: A negative value for a cause component denotes that the effect of change over time in sex differences in mortality due to that cause of death served to narrow the sex gap in life expectancy; a positive sign implies the opposite effect.

Source: Author's computations based on data from the World Health Organisation, www.who.org . 


\subsection{Age Decomposition of the Sex Differential in Life Expectancy}

Period shifts in life expectation at birth are usually not equally attributable to change in all age groups in the life table (Arriaga 1984; Kannisto et al. 1994; Manton 1982; Fries 1980; Vaupel and Canudas Romo 2003; Murthy 2005); therefore, a further aspect of the decomposition analysis considers the contribution of mortality differences within age categories to the sex difference in life expectation at birth. Whereas the earlier decomposition focused on the contribution of causes of death, the factor of interest here is age. ${ }^{21}$ Specifically, the female-male difference in life expectancy at birth is decomposed into the contribution of five age vector factors: (1) age $0-14$, (2) age 15-34, (3) age 35-54, (4) age 55-74, and (5) age 75+. Through this approach one is able to address the question: "How much of the observed female-male difference in life expectancy at birth within a given time period is attributable to sex difference in mortality in given age categories?" 22 A related question is: "How much of the observed change between periods (i.e., narrowing) in life expectancy at birth is attributable to change in sex differences in mortality in given age categories?"

Age decompositions for Canada and Austria for the interval between 1980/81 and 2000/2001 are shown in Table 5. In both nations, the female advantage in average length of life rises with age, though declining somewhat at age $75+$. In Canada, the largest contribution to the differential is due to age 55-74. About 52 per cent of the change in the life expectancy difference between females and males is due to reduced sex differences in mortality in this age class. ${ }^{23}$ The next largest contributions are associated with the age categories of 35-54 (about 23 per cent) and 15-34 (about 20 per cent). The youngest age group $(<15)$ shows a relatively small effect $(9$ per cent). It is interesting to note that mortality differences in the oldest age group $(75+)$ serve to expand the female advantage in

21 For a more detailed presentation of the age decomposition procedure see Das Gupta (1993:4649).

22 A similar approach is would be to decompose sex differences in partial expectation of life (PEL) within broad age categories. PEL for the age interval 15 to 44 is the average number of years lived in the age interval 15 to 44 by those who survive to age 15 , and it is clear that the maximum value of the expected number of years lived in this interval is 30 years (Trovato and Lalu 1988). Decomposition of age-specific PEL differences between females and males produced similar results to the age decompositions in Table 5.

23 Further analysis revealed that the relatively large reductions in the sex differentials in life expectancy for 55-74 year olds in Canada and Austria over the two points in time considered are accounted mainly by reduced sex gaps in heart disease mortality. Change in sex mortality differences due to lung cancer and "other" circulatory diseases are also important, but tend to be notably weaker in their contributions. The effect of accidents/violence sex gaps in mortality is relatively minor in the ages below 15 , though it is of some importance for those in the age range of 15-34. For this age group, the contribution of this cause is notably stronger in Austria than in Canada. 
Table 5:

Age decomposition of the female-male difference in life expectancy (the contribution of mortality differences within a given age group to the F-M difference in life expectancy at birth and its change between specified periods); Canada and Austria

\begin{tabular}{|c|c|c|c|c|}
\hline Canada & $\begin{array}{l}\text { Contribution (years } \\
\text { of life expectancy) }\end{array}$ & $\begin{array}{l}\text { Contribution (years } \\
\text { of life expectancy) }\end{array}$ & Change & \\
\hline Age group & 1981 & 2000 & $1981-2000$ & $\%$ \\
\hline$<15$ & 0.310 & 0.128 & -0.182 & -9.2 \\
\hline $15-34$ & 0.902 & 0.499 & -0.403 & -20.3 \\
\hline $35-54$ & 1.091 & 0.639 & -0.452 & -22.8 \\
\hline $55-74$ & 3.210 & 2.172 & -1.038 & -52.4 \\
\hline $75+$ & 1.816 & 1.909 & 0.093 & 4.7 \\
\hline Total & 7.329 & 5.347 & -1.982 & 100.0 \\
\hline Austria & $\begin{array}{l}\text { Contribution (years } \\
\text { of life expectancy) }\end{array}$ & $\begin{array}{l}\text { Contribution (years } \\
\text { of life expectancy) }\end{array}$ & Change & \\
\hline Age group & 1980 & 2001 & $1980-2001$ & $\%$ \\
\hline$<15$ & 0.434 & 0.170 & -0.264 & -19.4 \\
\hline $15-34$ & 1.031 & 0.602 & -0.429 & -31.6 \\
\hline $35-54$ & 1.620 & 0.991 & -0.629 & -46.3 \\
\hline $55-74$ & 3.142 & 2.705 & -0.437 & -32.2 \\
\hline $75+$ & 0.954 & 1.354 & 0.400 & 29.4 \\
\hline Total & 7.181 & 5.822 & -1.359 & 100.0 \\
\hline
\end{tabular}

Source: Author's computations based on data from the World Health Organisation, www.who.org .

life expectancy over males by about 5 per cent. In Austria, the influence of this age class is even more pronounced ( 29 per cent). Moreover, the contributions of the three youngest age groups are notably larger than in Canada. For instance, the age category 35-54 accounts for about 46 per cent of the narrowing in life expectancy as compared to about 23 per cent in Canada. It would appear that mortality change among younger adults in Austria has played a more prominent role than in Canada in reducing the sex gap in life expectancy at birth between the early 1980 s and around the turn of the new millennium.

\subsection{Smoking-related Mortality and Narrowing Sex Gap in Life Expectancy}

As mentioned earlier, in the industrialised countries the male smoking epidemic started earlier in the $20^{\text {th }}$ century than it did for females. However, in recent decades smoking has become less popular among men in many Western societies while among women its prevalence has been rising. Consequently, during recent decades lung cancer death rates have tended to level off and even decline for men but have been rising for women (Lopez, Caselli and Valkonen 1995; Waldron 1995; Nathanson 1995). It is therefore reasonable to assume that reductions in the 
sex difference in life expectancy since the early 1980s reflect shifts in past smoking behaviour by men and women (Pampel 2001a, 2002, 2003). From the decomposition analysis it may be concluded that change in sex differences in lung cancer and other types of mortality associated with smoking, including heart disease, other circulatory conditions, and other forms of cancer, are indeed key factors underlying observed shifts in the size of the sex differential in longevity. At the same time, however, the results are not consistent with the view that all of the observed narrowing of the life expectancy gap between men and women is solely attributable to convergence in male and female smoking-related mortality because the combined contributions of accidents and violence and cirrhosis of the liver have also been substantial, especially in the context of Austria. ${ }^{24}$

\section{Further Analysis}

Analysis of hypotheses 3-6 is based on zero-order correlations among a number of variables relevant to this analysis. The use of correlations is not ideal, but is judged appropriate since the number of data points is insufficient to apply multiple regression (for each country, there are four discrete points of observation, for a total of 8 cases). ${ }^{25}$ This part of the investigation is necessarily suggestive, and the model in Figure 3 is viewed only as an organising framework, subject to further verification with a large sample of countries. Data on smoking prevalence for men and women are from Nicolaides-Bouman and colleagues (1993). The index of gender role traditionalism is a composite measure

24 Using the decomposition results in Table 4, two sets of calculations were produced to assess indirectly the possible contribution of convergence in smoking-related mortality to the observed narrowing of sex differences in life expectancy between 1980 and 2001 in Austria, and between 1981 and 2000 in Canada. In both scenarios the contribution of lung cancer was assumed to reflect convergence in smoking-related mortality between men and women (i.e., it is assumed that smoking fully accounts for lung cancer mortality). In the first computation, one half of the contribution of heart disease and of "other" circulatory ailments is also assumed to reflect convergence in smoking-related mortality. In the second calculation, three quarters of the combined contribution of heart disease and "other" circulatory is assumed to reflect convergence in smoking-related mortality. From these computations, it was estimated that convergence in smoking-related mortality is likely responsible for about one half to two thirds of the observed narrowing of the sex difference in life expectancy at birth in Canada. In Austria, these calculations suggest that approximately 25 to 34 per cent of the convergence in the sex difference in longevity is due to convergence in sex differences in mortality from smoking-related causes of death (as defined here). By comparison, the combined contribution of convergence in mortality due to accidents, violence, suicide, and cirrhosis of the liver, accounted for about one third of the narrowing of the sex gap in Canada, and for about 64 per cent in Austria. Thus, the role of smoking convergence appears to have been a more important factor in Canada, while the non-medical (external) causes of death would seem to have played a larger role in Austria.

25 There are four periods $(1970 / 71,1980 / 81,1990 / 91,2000 / 2001)$ of observation and 2 countries with respect to male and female life expectancy, for a total of 8 data points. 
comprising the total fertility rate and the crude marriage rate, each lagged by twenty years. These variables were first converted to their standardised scores, then combined and divided by two to form the index (see footnote in Table 6). The assumption behind the use of these variables to compose this index is that in times of high fertility and marriage rates in a society the lives of women are conditioned strongly by traditional expectations that emphasise domesticity (Aries 1980; Davis 1984; Shorter 1975; Caldwell 1981; Lesthaeghe and Surkyn 1988). In such contexts women would be less inclined to participate in behaviours that challenge traditional conventions, including cigarette smoking (Vallin 1993).

The first row in Table 6 looks at the association of time period with other variables. Consistent with expectation, the female-male difference in life expectancy at birth is inversely correlated with time. Moreover, while the ratio of female to male smoking prevalence in the past (i.e., F/M smoke (t-20)) has been increasing over time $(\mathrm{r}=0.674)$, it is clear that the change in this ratio is determined more by reductions in male smoking prevalence (the correlation of time with male smoking is -0.829) than increased smoking among women (correlation of time with female smoking is only 0.371 ). The relationship of time with the index of gender role traditionalism (GRT) is negative $(r=-0.955)$, and that of time with female labour force participation (FLFPR) is positive ( $\mathrm{r}=$ 0.890).

Based on the hypotheses introduced earlier, a negative association between the ratio of female to male smoking prevalence in the past with the female-male difference in life expectancy is anticipated. The second row of Table 6 confirms this expectation $(\mathrm{r}=-0.639)$. However, of the two components of this ratio, only the male smoking variable is statistically significant $(\mathrm{r}=0.812)$, suggesting that male smoking is of greater importance in accounting for the sex gap in life expectancy than is female smoking. It was also posited that gender role traditionalism in society would be positively related to the sex differential in life expectation. Under more traditional contexts, female life expectancy would surpass male life expectancy to a larger degree than in less traditional contexts. The computed zero-order correlation between these two variables is in the anticipated direction $(\mathrm{r}=0.890)$. Of related interest is the inverse association between female labour force participation and gender role traditionalism $(\mathrm{r}=$ 0.952 ).

Concerning the possible association of female labour force participation with the sex differential in longevity, the computed correlation is -0.917 , suggesting that some aspect(s) of labour force involvement among women may be related to factors that serve to narrow the sex differential in life expectancy. One possible condition underlying this association may involve increased mortality risk from accidents as women engage in more varied occupations (e.g., construction, transport, etc.). This however should not exclude the reality that women's involvement in the paid economy also engenders psychological, social, and economic benefits and offers women a wider range of role options in society 
Table 6:

Relevant zero-order correlations among variables in this analysis

\begin{tabular}{|c|c|c|c|c|c|c|}
\hline Variables & $\mathrm{Fe} 0-\mathrm{Me} 0$ & $\begin{array}{c}\mathrm{F} / \mathrm{M} \\
\text { smoke } \\
(\mathrm{t}-20)\end{array}$ & $\begin{array}{c}\mathrm{F} \\
\text { smoke } \\
(\mathrm{t}-20)\end{array}$ & $\begin{array}{c}\mathrm{M} \\
\text { smoke } \\
(\mathrm{t}-20)\end{array}$ & $\begin{array}{l}\text { GRT } \\
\text { index } \\
(\mathrm{t}-20)\end{array}$ & $\begin{array}{c}\text { FLFPR } \\
(\mathrm{t}-20)\end{array}$ \\
\hline 1. Time period & $-.896 *$ & $.674 * * *$ & .371 & $-.829 *$ & $-.955^{*}$ & $.890 *$ \\
\hline 2. F/M smoke (t-20) & $-.639 * * *$ & & & & -.496 & \\
\hline 3. M smoke (t-20) & $.812 *$ & & & & & \\
\hline 4. F smoke (t-20) & -.333 & & & & & \\
\hline 5. GRT index $(\mathrm{t}-20$ & $.890 *$ & -.496 & -.143 & & & $-.952 *$ \\
\hline 6. FLFPR $(\mathrm{t}-20)$ & $-.917 *$ & .397 & .018 & & & \\
\hline Means & 6.681 & 0.503 & 22.50 & 47.25 & 0.000 & 38.46 \\
\hline S.D. & 0.645 & 0.243 & 9.99 & 9.95 & 0.794 & 10.23 \\
\hline
\end{tabular}

$* \mathrm{p} \leq .01 ; \quad * * \mathrm{p} \leq .05 ; \quad * * * \mathrm{p} \leq .10$

Note: Definition of variables: Time (four points of observation, as described in the text); $\mathrm{Fe} 0-\mathrm{MeO}$ (the difference in life expectancy at birth between females and males, where $\mathrm{MeO}$ and $\mathrm{Fe} 0$ are male and female life expectancy at birth, respectively); $F / M$ smoke ( $t-20)$ (the ratio of female to male smoking prevalence at $\mathrm{t}-20$ years ago in relation to each period of observation between 1970/71 and 2000/2001; in other words this variable is lagged 20 years); $F$ smoke ( $t$-20) (female smoking prevalence at t-20 years ago); $M$ smoke ( $t$-20) (male smoking prevalence at t-20 years ago); GRT index ( $t$-20) (an index of gender role traditionalism, lagged 20 years; it is a composite index of the $T F R_{(t-20)}+$ Crude marriage rate $(t-20)$ per 100,000 population. Each variable was transformed to its $\mathrm{Z}$ scores, and these were then added together and divided by 2); FLFPR ( $t$-20) (the female labour force participation rate for women aged 15-64, per 100, lagged 20 years). The smoking prevalence figures for men and women had to be estimated for 1951 in Canada, and for 1950 and 1960 for Austria due to lack of available data. For Canada, the United States smoking prevalence for 1954 was used. For Austria 1950 and 1960 , values were estimated on the basis of the observed trends between the early 1970s and the mid-1990s, and observations based on other western European countries around these two points in time. The derived estimates for these two years are as follows: $1950($ males $=60.0$; females $=9.0) ; 1960($ males $=57.0$; females $=12.0)$. Data sources: Male and female life expectancies are from computed life tables using data from the World Health Organisation (see text). The other variables were derived from the following sources. Total Fertility Rate: Statistics Canada (1993a); Keyfitz and Flieger (1990). Crude Marriage Rate per 1000 population: Statistics Canada (1993b); Council of Europe (2002: 49). Female Labour Force Participation Rates: Riddell (1985); Statistics Austria (2005: 180). Female/Male smoking prevalence ratio: derived from data in Nicolaides-Bouman et al (1993).

(Pampel and Zimmer 1989; Repetti, Matthews and Waldron 1989; Schoen et al. 2002). From the other correlations in Table 6 , female labour force participation and female smoking prevalence appear to be unrelated; the relevant associations failed to reach statistical significance. This is also true with respect to gender role traditionalism and the sex ratio of smoking prevalence.

Given the importance of smoking to mortality and longevity, Figure 4 examines in greater detail the association of past smoking trends for men and women with change in sex differences in all-cause mortality rates across selected age categories. Specifically, the graphs in this figure look at the relationship between sex differences in smoking at t-20 years ago (i.e., the ratio of female to male smoking prevalence at $\mathrm{t}-20$ ) and sex differences in death rates at ages 40-44, 50-54, and 60-64 (measured as male/female death rate ratios at time $\mathrm{t}$, where $\mathrm{t}=$ 1970/71, 1980/81, 1990/91, and 2000/2001). In general, this information for 
Figure 4:

Relationship between female/male smoking prevalence ratios lagged by 20 years (f/m $\operatorname{SMK}(\mathrm{t}-20)$ ), and three male/female age-specific death rate ratios (Mdr/Fdr) for ages 40-44, 50-54, and 60-64, at time period (t) in Canada and Austria
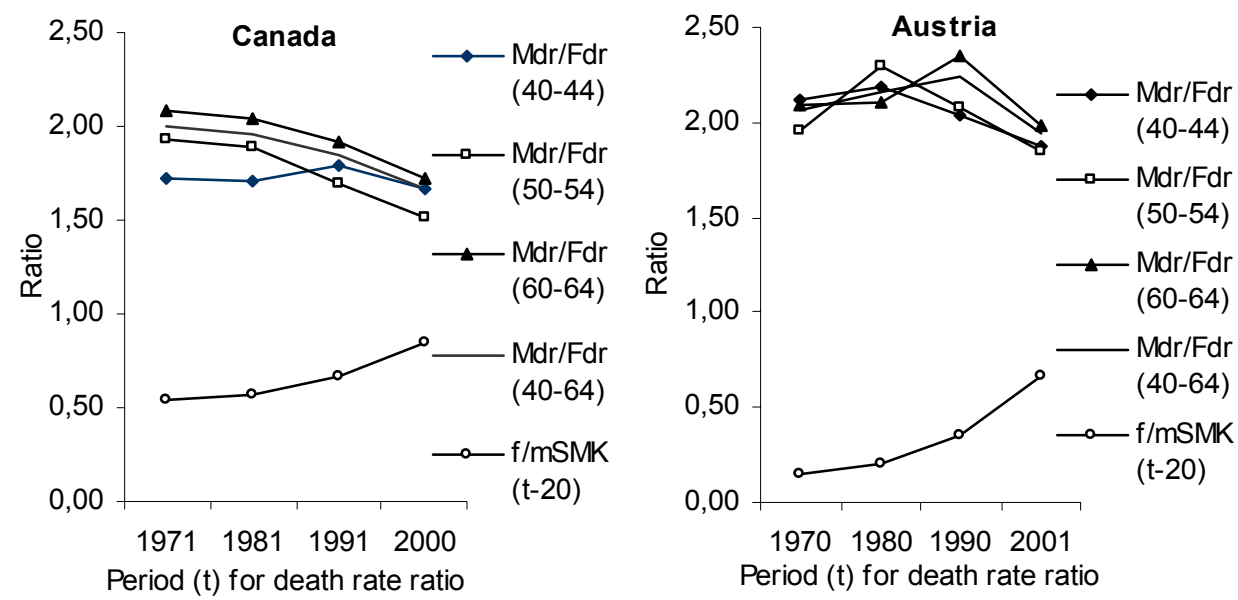

Note: (t) for the smoking variable for Canada is 1951, 1961, 1971, 1981, and for Austria it is 1950, 1960, 1970, 1980 .

The zero-order correlations across both countries of the smoking variable with each of the age-specific death rate ratios are as follows: $40-44=-0.883 ; 50-54=-0.848 ; 60-64=-0.733 ; 40-64=-0.850$.

Canada and Austria reinforces the notion that sex differences in smoking prevalence in the past and current sex differences in all-cause mortality among adults between the ages of 40 and 64 are associated in a predictable way: The greater the ratio of female to male smoking prevalence at $t-20$ years ago, the lower the male/female death rate ratio at time t. Stated differently, as overall smoking prevalence for females goes up in relation to men, the relative risk of mortality for men at approximately twenty years later declines, presumably as a function of slowed mortality improvements in females due to increased smokingrelated morbidity and deaths (e.g., lung cancer and vascular diseases).

\section{Discussion}

In high-income countries in the West the sex differential in life expectancy widened during most of the $20^{\text {th }}$ century. However, in many such contexts this long established differential peaked around 1980 and has since followed a declining trend. The present investigation looked at the continuation of this phenomenon into the early years of the new millennium in Canada and Austria. It was hypothesised that being in the fourth stage of epidemiological transition, the sex gap in longevity in these two countries would be explained mostly by 
differences in chronic diseases and most of the contribution to this would be by older adults. The decomposition analysis executed here revealed that a large portion of the sex gap in these two countries was accounted for by change in sex differences in heart disease mortality, which along with cancer is a leading cause of premature death. Convergence in lung cancer death rates between men and women has played an important role as well, though to a lesser degree than heart disease. Notwithstanding men's generally higher death rates as compared to women, men in Canada and Austria have managed, over recent years, to close some of their relative disadvantage from these major causes of death. As anticipated, a large portion of the observed change in the sex differential between women and men is specific to the contribution of mortality differences among older adults. Another hypothesis emphasised the relevance of external types of mortality (i.e., social pathologies). The decompositions results are consistent with the proposition that accidents and violence constitute an additional important factor in the explanation of sex differences in life expectancy and their change over time in Canada and Austria. In a comparative sense, the combined effects of heart disease and lung cancer have been more pronounced in Canada than in Austria, though in Austria, accidents and violence as a component of the sex difference in life expectancy has been of greater importance than in Canada. The reason underlying this difference between these two societies remains open to further investigation.

Some of the literature in this area of inquiry has focused on how change in the position of women relates to change in the sex differential in mortality. The analysis in the present study indicated that a significant part of the reductions in the sex differential in life expectancy in recent years has obtained from largerthan-expected mortality improvements in men as compared to women. This suggests that greater attention should be directed to how the male role in society may be changing and how this may relate to improvements in their survival probabilities. An important question in this regard pertains to change in men's mortality risk from not only lung cancer (mostly attributable to smoking), but also accidents and violence.

Concerning the role of smoking in differential mortality and longevity the analysis based on correlations, though limited, lends support for the proposition that convergence in smoking prevalence between men and women has been an important factor underlying reduced sex differences in life expectancy at birth over recent years. However, if one looks at the individual components of this measure (the ratio of female to male smoking prevalence) it appears that reductions in male smoking prevalence have been of greater importance in this than the effects of increased smoking in women.

On the question of whether convergence in smoking-related mortality fully underlies convergence in life expectancy between men and women, this analysis indicates that smoking differences are undoubtedly important in this respect. It would seem that in the adult ages between 40 and 65 mortality associated with 
prolonged tobacco consumption is a principal causal source of the sex differential in mortality. Thus, change in smoking behaviour among men and women must explain a large portion of the observed change in the sex differential in life expectancy. However, as shown in the decomposition analysis, smoking could not account for all of the observed narrowing of the gap in life expectancy. Beside the contributions of chronic conditions, of which many such diseases are linked to smoking, a sizeable part of the reductions in the sex gap is also attributable to the combined contributions of convergence in male and female mortality from accidents and violence and cirrhosis of the liver, which bear no, or limited, direct relationship to cigarette smoking.

Another aspect of this investigation concerned itself with the possible relevance of factors associated with change in the status of women in society and its possible link to female smoking and with change in the sex difference in longevity. The correlation analysis indicated that while increased female labour force participation is not significantly associated with female smoking, it is inversely correlated with sex differences in life expectancy. Thus, aspects of occupational change in women's lives may be detrimental to the pace of life expectancy improvements in relation to men. In view of the inconsistent results in the literature concerning this variable (Nathanson 1995; Pampel and Zimmer 1989; Waldron 1991) further analysis would be necessary at both micro and macro levels, within and between countries. What features of change in women's labour force participation act to improve their health and longevity? What features of women's experience in the labour force act to produce negative impacts on their health and longevity? How does women's labour force participation affect men in terms of their health and mortality risk?

It was also shown that a measure of gender role traditionalism in society did not correlate with female smoking prevalence. In a general sense this finding is not supportive of the proposition that change in the position of women in society affects the extent to which women smoke. Perhaps, as argued by Pampel (2002, 2003), changes in female smoking prevalence are more a function of diffusion processes rather than shifts in degree of gender role traditionalism or gender equity in society (Nathanson 1995).

Lastly, one may speculate on the possible future course of the sex differential in longevity. Will the recent narrowing trend continue, or will the differential revert to its past form and widen? One view proposes that once the female smoking epidemic, currently underway and at different points of development depending on the country, peaks and eventually subsides, smoking-related mortality for females (currently on the rise) should stabilise and then drop, at which point the sex gap in survival would revert to the traditional pattern of expanding differences in favour of women (Pampel 2002). Of course, this proposition cannot be verified fully until more data become available over the course of the next several decades or beyond. An alternative perspective would see future trends in mortality and life expectancy among men and women as 
dependent not only on smoking differentials but also to a significant degree on change in sex differences in other life style habits and behaviours that impact health in the long term (Waldron 1995). To the extent that sex differences in cancer and heart disease mortality are dependent on additional factors beside prolonged tobacco use, improved health habits in men should translate into further male gains in survival, even in a context of widespread reductions in the prevalence of smoking among females. And given the importance of accidents, violence and suicide as causes of premature death in men, further improvements in risk from these would also enhance male life expectancy and thus engender further reductions in the difference in life expectation between men and women. ${ }^{26}$

\section{Acknowledgements}

Many thanks to N. M. Lalu and Dave Odynak of the Population Research Laboratory, University of Alberta, and Nils Heyen (University of Bielefeld, Germany) for their valuable computing and research assistance throughout this study. Special thanks also to the two anonymous reviewers for their constructive comments and suggestions for revision. It goes without saying that responsibility for the content of this work rests solely with the author. This research was funded by a Social Science Research grant from the University of Alberta.

26 The investigation of current sex differences in health behaviours based on representative sample surveys can provide useful insight into possible sex differences in morbidity and mortality in the future. Epidemiological cohort studies have shown that health status at baseline predicts health status and survival chances later in life, and that negative health behaviours during the life course, such as cigarette smoking, excessive alcohol consumption, poor diet and lack of exercise, are detrimental to one's health and life span (Peters et al. 2003; Fontaine et al. 2003). In such studies psychosocial factors have also been shown to be important in predicting health status and mortality probabilities (House, Landis and Umberson 1988; Wilkinson 1996; Berkman and Syme 1979; Brockmann and Klein 2004; Rogers, Hummer and Nam 2000; Idler and Kasl 1992; Marmot et al. 1997; Eaker et al. 2004; Stansfeld et al. 2002). 


\section{References}

Acsadi, G. and J. Nemeskeri. 1970. History of Human Life Span and Mortality. Budapest: Akademiai Kiado.

Anderson, R. N., A. M. Minino, D. L. Hoyert, and H. M. Rosenberg. 2001. "Comparability of Cause of Death Between ICD-9 and ICD-10: Preliminary Estimates." National Vital Statistics Reports 49 (2) (May 18, 2001). Hyattsville, Maryland: National Center for Health Statistics.

Andreev, K. 2000. Sex Differentials in Survival in the Canadian Population, 1921-1997: A Descriptive Analysis with Focus on Age-Specific Structure. Descriptive Findings." Demographic Research 3 (12) (article 12) <<http://www.demographicresearch.org/Volumes/Vol13/12>>

Aries, P. 1980. "Two Successive Motivations for the Declining Birthrate in the West." Population and Development Review 6: 645-650.

Arriaga, E. E. 1984. "Measuring and Explaining the Change in Life Expectancies." Demography 21(1): 83-96.

Bartecchi, C. F., T. D. MacKenzie, and R. W. Schrier. 1994. "The Human Costs of Tobacco use. Part I.” New England Journal of Medicine 330 (13): 907-912.

Belanger, A. 2003. Report on the Demographic Situation in Canada 2002: Current Demographic Analysis. Ottawa: Minister of Industries (Cat. no. 91-209-XPE).

Berkman, L. F. and S. L. Syme. 1979. "Social Networks, Host Resistance, and Mortality: A Nine-Year Follow-up Study of Alameda County Residents." American Journal of Epidemiology 109 (2): 186-204.

Bombard, J., A. Malarcher, M. Schooley, and A. MacNeil. 2004. "State-Specific Prevalence of Current Cigarette Smoking Among Adults---United States, 2003." Journal of the American Medical Association 292 (24) (December 22/29): 2966-2967.

Boyle, P., A. d'Onofrio, P. Maisonneuve, G. Severi, C. Robertson, M. Tubiana, and U. Veronesi. 2003. "Measuring Progress Against Cancer in Europe: Has the 15\% Decline Targeted for 2000 Come About?” Annals of Oncology 14: 1312-1325.

Brockmann, H. and T. Klein. 2004. "Love and Death in Germany: The Marital Biography and its Effect on Mortality." Journal of Marriage and the Family 66: 567-581.

Caldwell, J. 1981. A Theory of Fertility Decline. New York: Academic Press.

Canadian Cancer Society. 2005. Progress in Cancer Control Over the Past Few Decades. $<<\mathrm{http}$ ://www.cancer.ca/ccs/internet/standardpf/>>

Caselli, G., F. Meslé, and J. Vallin. 2002. "Epidemiologic Transition Theory Exceptions." Genus 58 (1): 9-52.

Coale, A. J. 2003. "Increases in Expectation of Life and Population Growth." Population and Development Review 29 (1): 113-120.

Council of Europe 2002. Recent Demographic Developments in Europe. Strasbourg: Council of Europe Publishing

Das Gupta, P. 1993. Standardization and Decomposition of Rates: A User's Manual. U.S. Bureau of the Census, Current Population Reports, Washington, D.C., U.S. Government Printing Office.

Davis, K. 1984. "Wives and Work: Consequences of the Sex Role Revolution." Population and Development Review 10 (3): 397-417. 
Doll, R. and R. Peto. 1981. "The Causes of Cancer: Quantitative Estimates of Avoidable Risks of Cancer in the United States Today." Journal of the National Cancer Institute 66: 1191-1308.

Durkheim, E. 1887[1951]. Suicide: A Study in Sociology (Translated by J. A. Spaulding, with an introduction by G. Simpson). New York: The Free Press.

Eaker, E. D., L. M. Sullivan, M. Kelly-Hayes, et al. 2004. "Does Job Strain Increase the Risk for Coronary Heart Disease or Death in Men and Women? The Framingham Offspring Study." American Journal of Epidemiology 159: 950-958.

El-Badry, M. A. 1969. "Higher Female than Male Mortality in some Countries of South Asia: A Digest." Journal of the American Statistical Association 64: 1234-1244.

Enterline, P. E. 1961. "Causes of Death Responsible for Recent Increases in Sex Mortality Differentials in the United States." Milbank Memorial Fund Quarterly 39:312-328

Fontaine, K. R., D. T. Redden, C. Wang, A.O. Westfall, and D.B. Allison. 2003. "Years of Life Lost Due to Obesity." Journal of the American Medical Association (January 8) 289 (2): 187-193.

Fries, J. F. 1980. "Aging, Natural Death, and Compression of Mortality." The New England Journal of Medicine 303: 130 - 135.

Hegmann, T. T., A. M. Fraser, R. P. Kenny et al. 1993. "The Effect of Age at Smoking Initiation on Lung Cancer Risk." Epidemiology 4: 444-448.

House, J., S., K. R. Landis, and D. Umberson. 1988. "Social Relationships and Health." Science 241 (4865): 540-545.

Idler, E. L. and S. V. Kasl. 1992. "Religion, Disability, Depression, and the Timing of Death." American Journal of Sociology 97: 1052-1079.

Johnson, N. L. and R. C. Eland-Johnson. 1980. Survival Models and Data Analysis. New York: John Wiley and Sons.

Kannisto, V., J. Lauritsen, A. R. Thatcher, and J. W. Vaupel. 1994. "Reductions in Mortality at Advanced Ages: Several Decades of Evidence from 27 Countries." Population and Development Review 20 (4): 793-810.

Keyfitz, N. 1968. Introduction to the Mathematics of Population. Massachusetts: Addison-Wesley.

Keyfitz, N. and W. Flieger. 1990. World Population Growth and Aging: Demographic Trends in the Late Twentieth Century. Chicago: The University of Chicago Press.

Lesthaeghe, R. and J. Surkyn. 1988. "Cultural Dynamics and Economic Theories of Fertility Change." Population and Development Review 14: 1-45.

Lopez, A. D., G. Caselli, and T. Valkonen. 1995. "Moving From Description to Explanation of Adult Mortality: Issues and Approaches.” Pp. 3-18 in A. D. Lopez, G. Caselli, and T. Valkonen (Eds.) Adult Mortality in Developed Countries: From Description to Explanation. Oxford: Oxford University Press.

Lopez, A. D. 1995. "The Lung Cancer Epidemic in Developed Countries." Pp.111-134 in A. D. Lopez, G. Caselli, and T. Valkonen (Eds.) Adult Mortality in Developed Countries: From Description to Explanation. Oxford: Oxford University Press.

Lopez, A. D. 1983. "The Sex Differential in Mortality in Developed Countries." Pp. 43120. In A. D. Lopez and L. T. Ruzicka (Eds.) Sex Differentials in Mortality: Trends, Determinants and Consequences. Canberra, Australia: Department of Demography, Australian National University Printing Press.

Luy, M. 2003. "Causes of Male Excess mortality: Insights from Cloistered Populations." Population and Development Review 29 (4): 647-676. 
Madigan, F. C. 1957. “Are Sex Mortality Differentials Biologically Caused?” Milbank Memorial Fund Quarterly 35(2): 202-223.

Manton, K. G. 1982. "Changing Concepts of Morbidity and Mortality in the Elderly Population." Milbank Memorial Fund Quarterly/Health and Society 60: 183-244.

McDonald, P. 2000. "Gender Equity in Theories of Fertility Transition." Population and Development Review 26 (3): 427-440.

McGinnis, J. M. and W. H. Foege. 1993. "Actual Causes of Death in the United States." Journal of the American Medical Association 270 2207-2212.

Marmot, G. G., H. Bosma, H. Hemingway, E. Brunner, and S. Stansfeld. 1997. "Contribution of Job-Control and Other Risk Factors to Social Variations in Coronary Heart Disease Incidence.” Lancet 350: 235-239.

Mokdad, A. H., J. S. Marks, D. F. Stroup, and J. L. Gerberding. 2004. "Actual Causes of Death in the United States, 2000." Journal of the American Medical Association (March 10) 291 (10): 1238-1245.

Murthy, P. K. 2005. A Comparison of Different Methods for Decomposition of Changes in Expectation of Life at Birth and Differentials in Life Expectancy at Birth." Demographic Research 12 (article 7, 14 April, 2005) <<http://www.demographicresearch.org $>>$.

Nagnur, D. 1986. Longevity and Historical Life Tables. 1921-1981 (Abridged): Canada and the Provinces. Ottawa: Minister of Supply and Services Canada (Cat. No. 89506).

Namboodiri, K. and C. M. Suchindran. 1987. Life Table Techniques and Their Applications. New York: Academic Press.

Nathanson, C. A. 1995. "The Position of Women and Mortality in Developed Countries." Pp. 135-157 in A. D. Lopez, G. Caselli, and T. Valkonen (Eds.) Adult Mortality in Developed Countries: From Description to Explanation. Oxford: Oxford University Press.

Nathanson, C. A. 1984. "Sex Differences in Mortality.” Annual Review of Sociology 10: 191-213.

Nicolaides-Bouman, A., N. Wald, B. Forey, and P. Lee. 1993. International Smoking Statistics: A Collection of Historical Data from 22 Economically Developed Countries. London: The Wolfson Institute of Preventive Medicine and Oxford University Press.

Noymer, A. and M. Garenne. 2000. "The 1918 Influenza Epidemic's Effects on Sex Differentials in Mortality in the United States." Population and Development Review 26 (3): 565-581.

Olshansky, S. J. and B. A. Ault. 1986. "The Fourth Stage of Epidemiologic Transition: The age of Delayed Degenerative Diseases." The Milbank Quarterly 46 (3): 355-391.

Omran A. R. 1971. "The Epidemiological Transition: A Theory of Epidemiology of Population Change." Milbank Memorial Fund Quarterly 49: 509-538.

Owen, I. P. F. 2002. "Sex Differences in Mortality Rate." Science 297 (20 September): 2008-2009.

Pampel, F. 2003. "Declining Sex Differences in Mortality from Lung Cancer in HighIncome Nations." Demography 40 (1): 45-65.

Pampel, F. 2002. "Cigarette use and the Narrowing sex Differential in Mortality." Population and Development Review 28 (1): 77-104.

Pampel, F. 2001a. "Cigarette Diffusion and Sex Difference in Smoking." Journal of Health and Social Behavior 42: 388-404. 
Pampel, F. 2001b. "Gender Equality and the Sex Differential in Mortality From Accidents in High Income Nations." Population Research and Policy Review 20: 397-421.

Pampel, F. and C. Zimmer. 1989. "Female Labor Force Activity and the Sex Differential in Mortality: Comparisons Across Developed Nations, 1950-1980." European Journal of Population 5: 281-304.

Perls, T. T. and R. C. Fretts. 1998. "Why Women Live Longer than Men." Scientific American Presents 9: 100-104.

Peron, Y. and C. Strohmenger. 1985. Demographic and Health Indicators: Presentation and Interpretation. Ottawa: Minister or Supply and Services Canada (catalogue No. 83-543E).

Peters, A., J. J. Barendregt, F. Willekens, J. P. Mackenbach, A. A. Mamun, and L. Bonneux. 2003. "Obesity in Adulthood and its Consequences for Life Expectancy: A Life-Table Analysis." Annals of Internal Medicine 138: 28-34.

Peto, R., A. D. Lopez, J. Boreham, M. Thun, and C. Heath Jr. 1992. "Mortality from Tobacco in Developed Countries: Indirect Estimation from National Vital Statistics." The Lancet 339 (May 23): 1268-1278.

Peto, R., A. D. Lopez, J. Boreham, M. Thun, and C. Heath Jr. 2000. Mortality From Smoking in Developed Countries 1950-2000: Indirect Estimates from National Vital Statistics. Oxford: Oxford University Press.

Pollard, J. H. 1988. "On the Decomposition of Changes in Expectation of Life and Differentials in Life Expectancy." Demography 25 (2): 265-276.

Population Reference Bureau. 2003 and 2004. World Population Data Sheet. Washington.

Preston, S. H. 1976. Mortality Patterns in National Populations. New York: Academic Press.

Preston, S. H., N. Keyfitz, and S. Schoen. 1972. Causes of Death Life Tables for National Populations. New York: Academic Press.

Ravenholt, R. T. 1990. “Tobacco's Global Death March.” Population and Development Review 16 (2): 213-240.

Repetti, R. L., K. A. Matthews, and Ingrid W. 1989. “Employment and Women's Health: Effects of Paid Employment on Women's Mental and Physical Health." American Psychologist 44 (11): 1394-1401.

Retherford, R. D. 1975. The Changing Sex Differential in Mortality. Westport/London: Greenwood Press.

Riddell, W. C. 1985. Work and Pay: The Canadian Labor Market: An Overview. Toronto: University of Toronto Press

Riley, J. C. 2001. Rising Life Expectancy: A Global History. Cambridge: Cambridge University Press.

Rogers, R. G., R. A. Hummer, and C. B. Nam. 2000. Living and Dying in the USA: Behavioral, Health, and Social Differentials of Adult Mortality. San Diego: Academic Press.

Rogers, R. G. and R. Hackenberg. 1987. "Extending Epidemiologic Transition Theory: A New Stage." Social Biology 34 (3-4): 234-243.

Salomon, J. A. and C. J.L. Murray. 2002. "The Epidemiologic Transition Revisited: Causes of Death by Age an Sex." Population and Development Review 28 (2): 205228.

Schoen, R., N. M. Astone, K. Rothert, N. J. Standish, and Y. J. Kim. 2002. "Women's Employment, Marital Happiness, and Divorce." Social Forces 81 (2): 643-662.

Shorter, E. 1975. The Making of the Modern Family. New York: Basic Books. 
Smith, D. W .E. 1993. Human Longevity. New York: Oxford University Press.

Stack, S. 2000a. "Suicide: A 15-year Review of the Sociological Literature. Part I: Cultural and Economic Factors." Suicide and Life-Threatening Behavior 30 (2): 145162.

Stack, S. 2000b. "Suicide: A 15-year Review of the Sociological Literature. Part II: Modernization and Social Integration Perspectives." Suicide and Life-Threatening Behavior 30 (2): 163-176.

Stack, S. and N. Danigellis. 1985. "Modernization and the Sex Differential in Suicide, 1919-1972." Comparative Social Research 8: 239-252.

Stansfeld, S.A., Fuhrer R., M.J. Shipley, et al. 2002. "Psychological Distress as a Risk Factor for Coronary Heart Disease in the Whitehall SII Study." International Journal of Epidemiology 31: 248-255.

Statistics Canada 1993a. Selected Birth and Fertility Statistics, Canada, 1921-1990. Ottawa: Minister of Industry, Science and Technology (Cat. No. 82-553)

Statistics Canada. 1993b. Selected Marriage Statistics, 1921-1990. Ottawa: Minister of Industry, Science and Technology (Cat. No. 82-552);

Statistics Austria. 2005. Statistisches Jahrbuch 2005. Vienna.

Stolnitz, G. 1956. "A Century of International Mortality Trends. Part II." Population Studies 10 (1): 17-42.

Trovato, F. and N. M. Lalu. 1998. "Contribution of Cause-Specific Mortality to Changing Sex Differences in Life Expectancy: Seven Nations Case Study." Social Biology 45 (1-2): 1-20.

Trovato, F. and N. M. Lalu. 1996a. "Narrowing Sex Differences in Life Expectancy in the Industrialized World: Early 1970s to Early 1990s." Social Biology 43 (1-2): 20-37.

Trovato, F. and N. M. Lalu. 1996b. "Causes of Death Responsible for the Changing Sex Differential in Life Expectancy Between 1970 and 1990 in Thirty Industrialized Countries." Canadian Studies in Population 23 (2): 99-126.

Tuljapurkar, S., N. Li, and C. Boe. 2000. "A Universal Pattern of Mortality Decline in the G7 Countries.” Nature 405 (15 June): 789-792.

UN Department of Economic and Social Affairs. 1973. The Determinants and Consequences of Population Trends. Volume I. New York: United Nations (ST/SOA/SER.A/50).

Vallin, J. 1993. "Social Change and Mortality Decline: Women's Advantage Achieved or Regained?” Pp. 190-212 in N. Federici, K. Oppenheim Mason, and S. Sogner (Eds.) Women's Position and Demographic Change. Oxford: Clarendon Press.

Vallin, J. 1983. "Sex Patterns of Mortality: A Comparative Study of Model Life Tables and Actual Situations with Special Reference to the Case of Algeria and France." Pp. 443-476 in A. D. Lopez and L. T. Ruzicka (Eds.) Sex Differentials in Mortality: Trends, Determinants and Consequences. Canberra: Australian National University, Department of Demography.

Van de Kaa, D. 2004. "Is the Second Demographic Transition a Useful Research Concept: Questions and Answers." Vienna Yearbook of Population Research 2004, Vienna Institute of Demography. Vienna: Austrian Academy of Sciences.

Van de Kaa, D. 1999. "Europe and its Population: The Long View." Pp. 1-76 in D. Van de Kaa, H. Leridon, G. Gesano, and M. Okolski (Eds.) European Populations: Unity in Diversity. Dordrecht, Netherlands: Kluwer Publishers.

Van de Kaa, D. 1987. Europe's Second Demographic Transition. Population Bulletin 42. Washington: Population Reference Bureau. 
Van Hoorn, W. and R. Broekman. 1999. "Uniformity and Diversity Scenarios for Mortality." Pp. 71-90 in J. de Beer and L. van Wissen (Eds.) Europe: One Continent, Different Worlds: Population Scenarios for the $21^{\text {st }}$ Century. Dordrecht, Netherlands: Kluwer Publishers.

Vaupel, J. W. and V. Canudas Romo. 2003. "Decomposing Change in Life Expectancy: A Bouquet of Formulas in Honor of Nathan Keyfitz's $90^{\text {th }}$ Birthday." Demography 40 (2): 201- 216.

Veevers, J. E. and E. M. Gee. 1986. "Playing it Safe: Accident Mortality and Gender Roles." Sociological Focus 19 (4): 349-360.

Verbrugge, L. M. 1976. "Sex Differentials in Morbidity and Mortality in the United States." Social Biology 23 (4): 275-296.

Waldron, I. 2000. "Trends in Gender Differences in Mortality: Relationships to Changing Gender Differences in Behavior and Other Causal Factors. Pp. 150-181 in E. Annandale and K. Hung (Eds.) Gender Inequalities in Health. Buckingham: Open University Press.

Waldron, I. 1995. "Contributions of Biological and Behavioral Factors to Changing Sex Differences in Ischaemic Heart Disease Mortality." Pp. 161-178 in A. D. Lopez, G. Caselli, and T. Valkonen (Eds.) Adult Mortality in Developed Countries: From Description to Explanation. Oxford: Oxford University Press.

Waldron, I. 1993. "Recent Trends in Sex Mortality Ratios for Adults in Developed Countries." Social Science and Medicine 36 (4): 451-462.

Waldron, I. 1991a. "Effects of Labor Force Participation on Sex Differences in Mortality and Morbidity." Pp. 17-38 in M. Frankenhaeuser, U. Lundberg, and M. Chasney (Eds.) Women, Work, and Health. New York: Plenum.

Waldron, I. 1991b. "Patterns and Causes of Gender Differences in Smoking." Social Science and Medicine 32 (9): 989-1005.

Waldron, I. 1986. "The Contribution of Smoking to Sex Differences in Mortality." Public Health Reports 101 (2): 163-173.

Waldron, I. 1976. "Why Do Women Live Longer than Men?" Social Science and Medicine 10: 349-362.

White, K. M. 2002. "Longevity Advances in High-Income Countries, 1955-96." Population and Development Review 28 (1): 59-76.

White, K. M. and S. H. Preston. 1996. "How Many Americans are Alive Because of Twentieth-Century Improvements in Mortality?" Population and Development Review 22 (3): 415-429.

Wilkinson, R. 1996. Unhealthy Societies: The Afflictions of Inequality. London and New York: Routledge.

Wilmoth, J. R. 1998. "The Future of Human Longevity: A Demographer's Perspective." Science 280: 395-397.

Wingard, D. L.1984. "The Sex Differential in Mortality Rates: Demographic and Behavioral Factors." American Journal of Epidemiology 115 (2): 205-216.

World Health Organization. 2003. Mortality Data Base. Geneva. <<www.who.org >>.

World Health Organization. 1998. World Health Statistics Annual 1996. Geneva.

Yanagishita, M. and J. M. Guralnik. 1988. "Changing Mortality Patterns That Led Life Expectancy in Japan to Surpass Sweden's: 1972-1982.” Demography 25 (4): 611-624. 


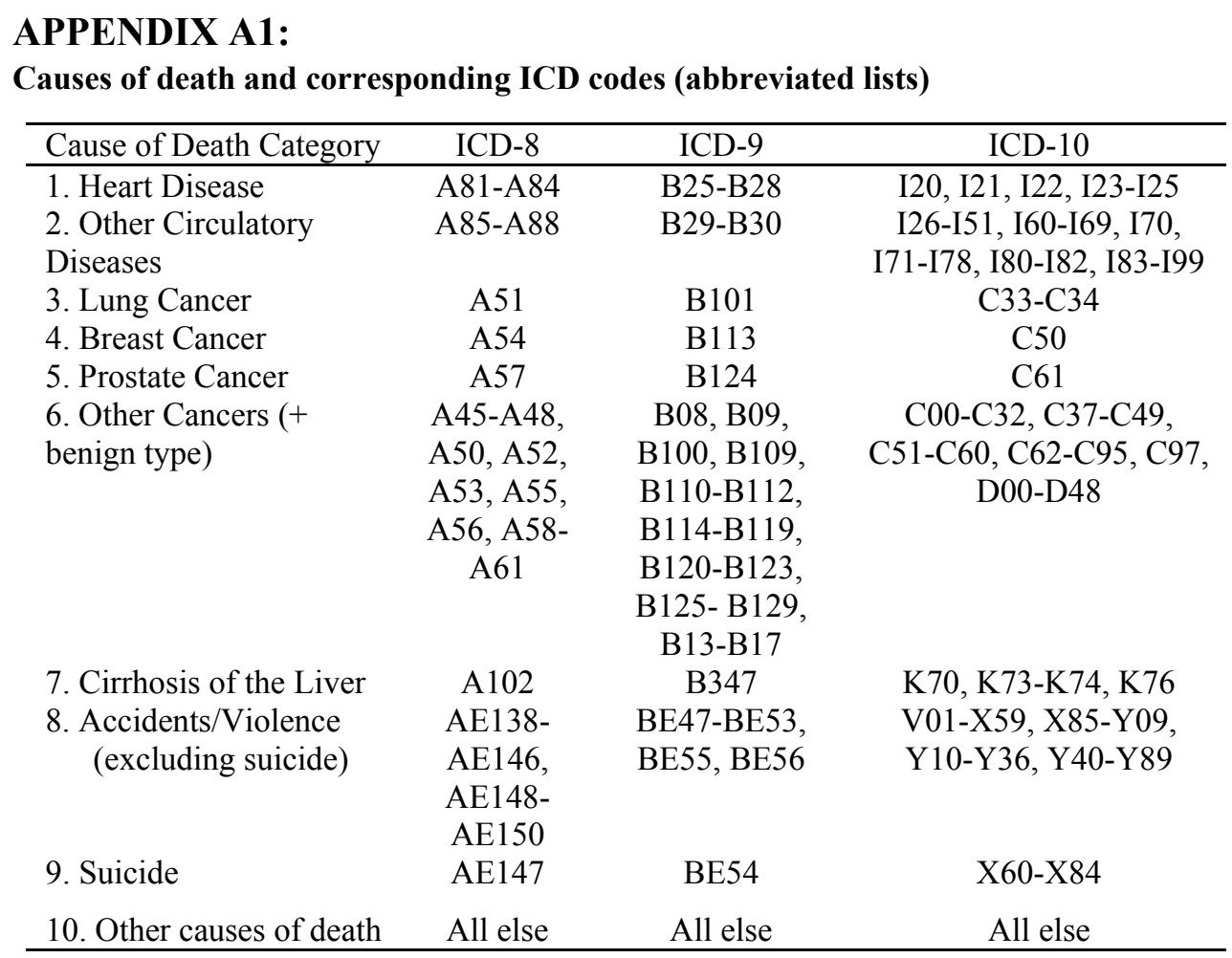

Note: For the four periods examined in this study, ICD-8 pertains to 1970 and 1971 ; ICD-9 to 1980 and 1981 ; ICD-10 to 2000 and 2001. 